\title{
The Use of Diamond for Energy Conversion System Applications: A Review
}

\author{
K. I. B. Eguiluz, ${ }^{1}$ J. M. Peralta-Hernández, ${ }^{2}$ A. Hernández-Ramírez, ${ }^{3}$ J. L. Guzmán-Mar, ${ }^{3}$ \\ L. Hinojosa-Reyes, ${ }^{3}$ C. A. Martínez-Huitle, ${ }^{4}$ and G. R. Salazar-Banda ${ }^{1}$ \\ ${ }^{1}$ Instituto de Tecnologia e Pesquisa e Programa de Pós-Graduação em Engenharia de Processos, Universidade Tiradentes, \\ 49032-490 Aracaju, SE, Brazil \\ ${ }^{2}$ Centro de Innovación Aplicada en Tecnologías Competitivas, Departamento de Investigación Ambiental, Omega-201, \\ Fraccionamiento Industrial Delta, 37545 León, Guanajuato, Mexico \\ ${ }^{3}$ Laboratorio de Fotocatálisis y Electroquímica Ambiental, Facultad de Ciencias Químicas, Universidad Autónoma de Nuevo León, \\ 64570 Monterrey, NL, Mexico \\ ${ }^{4}$ Departamento de Química, Centro de Ciências Exatas e da Terra, Universidade Federal do Rio Grande do Norte, \\ Lagoa Nova 59078-970 Natal, RN, Brazil
}

Correspondence should be addressed to G. R. Salazar-Banda, gianrsb@gmail.com

Received 1 May 2011; Revised 20 June 2011; Accepted 21 June 2011

Academic Editor: Yasuaki Einaga

Copyright $\odot 2012$ K. I. B. Eguiluz et al. This is an open access article distributed under the Creative Commons Attribution License, which permits unrestricted use, distribution, and reproduction in any medium, provided the original work is properly cited.

Catalytic layers of polymer electrolyte membrane fuel cell (PEMFC) electrodes are usually composed of platinum nanoparticles dispersed on an electron conductive carbon support, which can undergo several degradation processes like dissolution of Pt and carbon corrosion under PEMFC working conditions. In this context, the major advantage of conductive boron-doped diamond (BDD) surfaces is their mechanical and chemical stability. BDD is also considered as a good substrate for studying the intrinsic properties of deposited catalysts, avoiding some problems encountered with other substrates, that is, surface corrosion, oxide formation, or electronic interactions with the deposit. Thus, the first part of this review summarized the surface modification of BDD materials, with emphasis in different techniques, to improve the catalytic efficiency of supported catalysts for PEMFCs. In addition, it is known that graphite carbon or lithium metal alloys used in advanced lithium-ion high-energy batteries suffer morphological changes during the charge-discharge cycling, which in turn results in a very poor cycle life. Thus, the use of diamond materials in these applications was also reviewed, since they have very stable surfaces and exhibits excellent electrochemical properties when compared with other carbon forms like glassy carbon and highly oriented pyrolytic graphite.

\section{Introduction}

The continuous use of petroleum as the main source of energy has caused considerable atmospheric pollution and global warming. At the same time, with the continued climbing of crude oil price and increase of energy demand, research on alternative energy resources becomes an urgent task for scientists around the world. In that manner, electrochemists intensified their research in order to develop the fuel cell technology. Fuel cells can convert chemical fuels, including some renewable, directly into electricity. The main advantage of this technology over traditional energy production is that the fuel cell energy efficiency is Carnot cycle independent. Fuel cells, in particular polymer electrolyte membrane fuel cells (PEMFCs), represent an attractive technology to meet future energy needs because of their potentially high efficiency in converting stored chemical energy to electrical energy. However, their widespread deployment has been hampered by materials limitations, as exemplified in the catalysts by their high cost, intolerance to fuel contaminants, and degradation leading to short fuel cell lifetimes. The possible use of methanol and other small organic molecules as PEMFC fuels is promising because of their high energy density and ease of transport, compared to $\mathrm{H}_{2}$.

The catalytic layers of PEMFC electrodes are usually composed of platinum nanoparticles dispersed on an electron conductive carbon support, in weight ratios higher 
TABLE 1: Survey of recent publications on metal/metal oxide particles from microemulsions deposited onto BDD thin film electrodes with applications in fuel cells.

\begin{tabular}{|c|c|c|c|c|c|c|}
\hline Catalyst & $\begin{array}{c}\text { Microemulsion } \\
\text { system }\end{array}$ & Metal precursor & $\begin{array}{c}\text { Reducing/precipitating } \\
\text { agent }\end{array}$ & $\begin{array}{l}\text { Particle diameter } \\
(\mathrm{nm})\end{array}$ & Catalytic reaction & Reference \\
\hline $\mathrm{Pt}$ & BRIJ-30 $/$ n-heptane & $\mathrm{H}_{2} \mathrm{PtCl}_{6}$ & $\mathrm{NH}_{2} \mathrm{NH}_{2}$ & $2-3$ & Methanol oxidation & {$[20]$} \\
\hline Pt-Ru & BRIJ-301/n-heptane & $\mathrm{H}_{2} \mathrm{PtCl}_{6}, \mathrm{RuCl}_{3}$ & $\mathrm{NaBH}_{4}$ & $2-5$ & $\begin{array}{l}\text { Methanol and } \\
\text { ethanol oxidation }\end{array}$ & {$[21]$} \\
\hline Pt-Sn & BRIJ-301/n-heptane & $\mathrm{H}_{2} \mathrm{PtCl}_{6}, \mathrm{SnCl}_{2}$ & $\mathrm{NaBH}_{4}$ & $2-5$ & Ethanol oxidation & {$[22]$} \\
\hline $\mathrm{Pt} / \mathrm{Ru} / \mathrm{Sn}$ & BRIJ-301/n-heptane & $\begin{array}{c}\mathrm{H}_{2} \mathrm{PtCl}_{6}, \mathrm{RuCl}_{3}, \\
\mathrm{SnCl}_{2}\end{array}$ & $\mathrm{NaBH}_{4}$ & $2-5$ & $\begin{array}{l}\text { Methanol and } \\
\text { ethanol oxidation }\end{array}$ & {$[23]$} \\
\hline
\end{tabular}

${ }^{1}$ BRIJ-30: Polyoxyethylene (4) lauryl ether (non ionic surfactant).

than $10 \mathrm{wt} \%[1,2]$. Under PEMFC working conditions, the catalytic layers undergo several degradation processes: dissolution of platinum [3] and carbon corrosion [4], increase of the particle size due to agglomeration [5], and so forth. In this context, in recent years, conductive films of boron-doped diamond (BDD) have been used for many researches as an outstanding electrode material for electrosynthesis [6], a conductive support in electrocatalysis and mainly in environmental applications [7-13]. Borondoped diamond (BDD) exhibits attractive properties such as wide potential window, low background current, a high chemical and dimensional stability, making it feasible for many electrochemical processes [14]. Recently, Shao et al. [15], in a critical review about novel catalyst support materials for PEMFCs, discussed that BDD materials can be used as a potential support in these systems. In this context, the major advantage of conductive BDD is the mechanical and chemical stability that it offers to modify this substrate.

BDD can be considered as a good substrate for studying the intrinsic properties of deposited catalysts, avoiding the problems encountered with other common substrates, that is, surface corrosion, oxide formation, or electronic interactions with the deposit. This is advantageous for the fundamental study of electrocatalysis.

Part of the aims of this review is to summarize the basic surface modification of BDD materials, with emphasis on different techniques to improve the catalytic efficiency of supported catalysts for PEM fuel cells (methanol and ethanol oxidation) using BDD materials.

In addition, it is known that graphite carbon or lithium metal alloys used in advanced lithium-ion high-energy batteries suffer morphological changes during the chargedischarge cycling, which in turn results in a very poor cycle life. Thus, BDD electrode materials, that have very stable surfaces and exhibits excellent electrochemical properties when compared with other carbon forms like glassy carbon and highly oriented pyrolytic graphite, has been proposed as an alternative material for battery applications. Thus, the use of diamond materials in these applications is also reviewed.

\section{Application of Modified BDD Films for Fuel Cell Applications}

The deposition of metal or metal oxide clusters onto BDD film surfaces as nanoparticles is used to exploit the much higher catalytic activity of such nanoparticles using very small amounts only compared to the conventional bulk material [16]. Many deposition techniques have been tested in an effort to improve particle adherence and dispersion. A wide range of methods for nanoparticles synthesis has been explored. These methods are well known to be efficient ways to prepare particles and nanoparticles; however, the shape and size distribution of the obtained particles are strongly dependent on the synthesis technique. The deposition technique should be simple and yield good dispersion of the particles on the substrate surface. In this section we present a general review of the techniques used for the modification of BDD surfaces to studies as electrodes for fuel cell systems. Some fundamentals of each technology are also briefly discussed to better understand its advantages and limitations for the modification of BDD surfaces.

2.1. Microemulsion Synthesis. A microemulsion is defined as a thermodynamically stable isotropic dispersion of two immiscible liquids consisting of microdomains of one or both liquids stabilized by an interfacial film of surface active molecules. The microemulsion system is characterized by transparency (optical isotropic), droplet size (from 6 to $80 \mathrm{~mm}$ ), and stability (thermodynamic) [17, 18]. The synthesis of inorganic nanoparticles is usually carried out in water-in-oil microemulsions (w/o). The microemulsion method has been used as microreactors to produce nanoparticles with narrow size distribution, since the first work described by Boutonnet et al. [19]. Water-in-oil microemulsion consists in the coexistence of an excess water phase and the surfactant molecules which aggregate in the oil phase in the form of reverse micelle. The water core of these aggregates is surrounded by surfactant molecules which have the nonpolar part of their molecule towards the oil phase. In the water core of this aggregate metal salts can be solubilized. These metals will be then transformed into inorganic precipitates by using an appropriate reducing or precipitating agent. The final size and shape of the nanoparticles can be controlled by varying the water-tosurfactant molar ratio or by varying the microemulsion itself.

Since the development of the microemulsion technique [19], a few publications have been presented in which the technique has been used for the synthesis of metallic nanoparticles where the catalyst has been supported in BDD (Table 1). BDD has been investigated as substrate of 
Pt [20], Pt-Ru [21], Pt-Sn [22], and Pt-Ru-Sn [23]. The choice of $\mathrm{Pt}$ and Pt-based particles was motivated by its useful potential application in alcohol (methanol or ethanol) electro-oxidation.

Siné and Comninellis [20] obtained platinum nanoparticles by reduction of chloroplatinic acid $\left(\mathrm{H}_{2} \mathrm{PtCl}_{6}\right)$ with hydrazine at room temperature in a water-in-oil (w/o) microemulsion of tetraethylene glycol monododecylether (BRIJ-30)/n-heptane using a two microemulsion steps method. The catalyst displayed similar particle size 2$5 \mathrm{~nm}$. Platinum nanoparticles were deposited onto the BDD substrate putting of the suspension on the diamond substrate and the excess water was dried under nitrogen atmosphere. Nafion films were used to mechanically stabilize the electrode in order to avoid the detachment of Pt nanoparticles from the BDD surfaces by the addition of Nafion solution.

Anodic treatment at high overpotentials activates $\mathrm{Pt}$ deposit that is mechanically stabilized by a Nafion layer. Activation of the Pt deposit by hydroxyl radicals produced by water discharge becomes feasible when a Nafion layer is added to the BDD-Pt electrode. The polymer layer strongly stabilizes the particles under these conditions, and optimum activation times, for which activity reaches by a maximum, were found to be close to $3 \mathrm{~s}$ in all cases. Such activation resulted in enhancement of activity towards methanol electro-oxidation, due to additional cleaning of the particles by oxidation of the residual surfactant by electrogenerated hydroxyl radicals.

Subsequently, Siné and coworkers prepared bimetallic binary Pt-Ru [21], Pt-Sn [22], and ternary Pt-Ru-Sn [23] nanoparticles supported on BDD substrates by mixing the microemulsion with solid sodium borohydride as reducing agent.

They also used transmission electron microscopy (TEM) and X-ray photoelectron spectroscopy (XPS) techniques to characterize particle sizes and morphology and to determine the effective particle compositions and the identification of oxidation states of metals in the different samples, respectively. On the other hand, the morphology and microstructure of metal-BDD electrodes were characterized by X-ray diffraction (XRD), and the specific electrochemical surface activity and stability were analyzed by cyclic voltammetry $(\mathrm{CV}) . \mathrm{Pt} / \mathrm{Ru}$ nanoparticles of different compositions were synthesized by mixing appropriate ratios of $\mathrm{Pt}$ and $\mathrm{Ru}$ precursors in the aqueous phase of the microemulsion; and the size distributions obtained by them were similar for all the samples and the size domain of the particles was approximately $2-3 \mathrm{~nm}$ of diameter. In addition, $\mathrm{CV}$ was used as a surface analytical tool to provide information on the surface state of BDD-supported nanoparticles.

In fact, other syntheses were carried out by the same authors in order to understand the effect of particles size and morphology on the efficiency. Therefore, bimetallic $\mathrm{Pt} / \mathrm{Sn}$ particles of several compositions with theoretical atomic contents $\mathrm{Pt}_{80} \mathrm{Sn}_{20}, \mathrm{Pt}_{60} \mathrm{Sn}_{40}, \mathrm{Pt}_{50} \mathrm{Sn}_{50}, \mathrm{Pt}_{40} \mathrm{Sn}_{60}, \mathrm{Pt}_{20} \mathrm{Sn}_{80}$ were synthesized via the microemulsion method [22].

TEM micrographs of the catalysts revealed small isolated and well-spherical units of diameter in the $2-5 \mathrm{~nm}$ range, whereas XRD analyses confirmed the deposition of

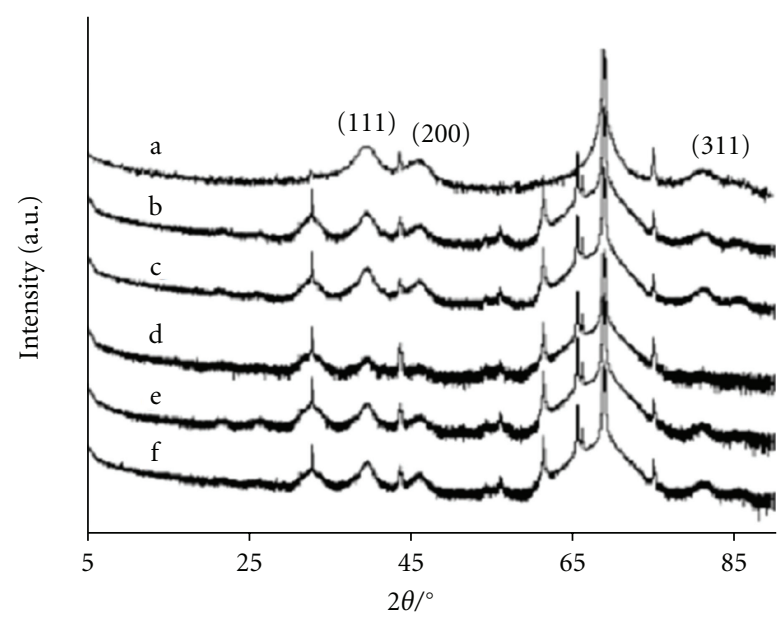

(a)

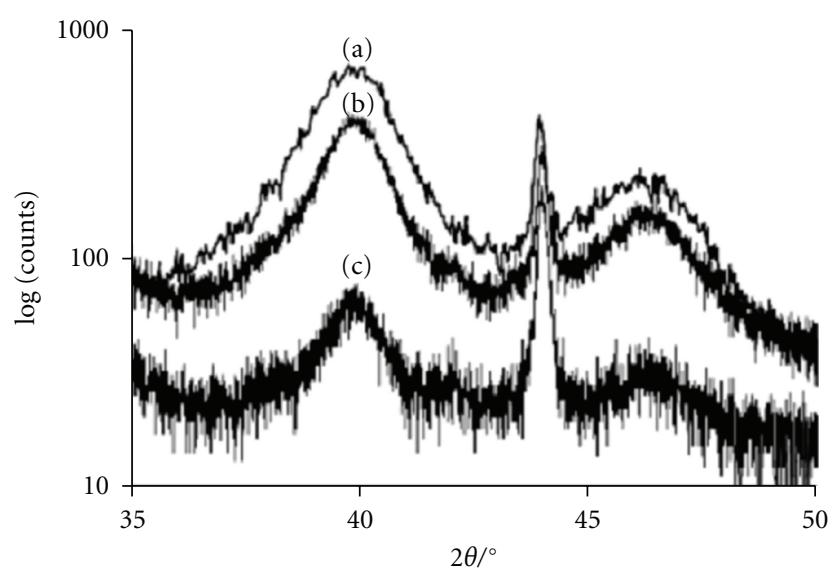

(b)

FIgure 1: (a) XRD patterns of microemulsion-synthesized $\mathrm{Pt} / \mathrm{Sn}$ nanoparticles deposited on BDD; (a) Pt, (b) $\mathrm{Pt}_{80} \mathrm{Sn}_{20}$, (c) $\mathrm{Pt}_{60} \mathrm{Sn}_{40}$, (d) $\mathrm{Pt}_{50} \mathrm{Sn}_{50}$, (e) $\mathrm{Pt}_{40} \mathrm{Sn}_{60}$ and (f) $\mathrm{Pt}_{20} \mathrm{Sn}_{80}$ nanoparticles. (b) XRD patterns of microemulsion-synthesized $\mathrm{Pt}$ (a), $\mathrm{Pt}_{80} \mathrm{Sn}_{20}$ (b) and $\mathrm{Pt}_{50} \mathrm{Sn}_{50}$ (c) nanoparticles deposited on BDD in the $\mathrm{Pt}(111)$ and $\mathrm{Pt}$ (200) reflections region (Reprinted with permission from [22]).

crystalline Pt and Sn structures together with the peaks attributed to diamond $\left(44^{\circ}\right.$ and $\left.75.3^{\circ}\right)$ and silicon $\left(70^{\circ}\right)$ from the substrate (Figure 1(a)). The (101), (200), (112), (211) (202), and (213) planes of Sn (located at $2 \theta$ values of $33.1^{\circ}, 56.5^{\circ}, 61.8^{\circ}, 66^{\circ}, 66.5^{\circ}$, and $86.7^{\circ}$, resp.) are also observed in Figure 1(a). Furthermore, the (111) and (200) peaks of Pt are well defined and discernable on all the XRD patterns and were not altered by the gradual addition of Sn in the particles. This indicates that there was no loss of crystallinity in the Pt lattice with two different crystalline phases coexisting as bimetallic nanoparticles rather than true alloys [22].

This result was confirmed with the data obtained in Figure 1(b). Peak displacements of Pt (111) and Pt (200) reflections were not observed for the contributions of $\mathrm{Pt}_{80} \mathrm{Sn}_{20}$ and $\mathrm{Pt}_{50} \mathrm{Sn}_{50}$ nanoparticles that clearly indicated that the microemulsion route leads to the formation of 
bimetallic nanoparticles rather than true alloys. The fact that $\mathrm{Pt} / \mathrm{Sn}$ nanoparticles were not true alloys seemed not to be a limitation to their use as electrocatalysts.

The Pt-rich bimetallic surfaces displayed the better electrocatalytic activities and the higher tolerance to $\mathrm{CO}$ poisoning, due to their superior alcohol adsorption properties at room temperature. In this sense, microemulsionsynthesized $\mathrm{Pt}_{80} \mathrm{Sn}_{20}$ nanoparticles can be considered as good electrocatalysts of ethanol oxidation [22].

compositions $(80: 10: 10)$ were synthesized by Siné et al. [23]. The particle size measured by TEM was in the $2-5 \mathrm{~nm}$ range. XPS analyses of $\mathrm{Pt}_{80} \mathrm{Ru}_{10} \mathrm{Sn}_{10}$ nanoparticles produced by microemulsion technique showed that the relative atomic amounts of $\mathrm{Pt}, \mathrm{Ru}$, and $\mathrm{Sn}$ in the nanoparticles were 90, 3, and 7\%, respectively. XPS Pt $4 \mathrm{f}$ spectra for $\mathrm{Pt} / \mathrm{Ru}, \mathrm{PtSn}$ and $\mathrm{Pt} / \mathrm{Ru} / \mathrm{Sn}$ alloy nanoparticles have shown that Pt4f binding energies for the $\mathrm{Pt} / \mathrm{Ru}$ and $\mathrm{Pt} / \mathrm{Sn}$ alloy nanoparticles were lower than those for clean Pt nanoparticles. The change in the electronic structure of the Pt component in the alloys $(\mathrm{Pt} / \mathrm{Sn}$ and $\mathrm{Pt} / \mathrm{Ru})$ could modify the Pt work function and thus weakens bonding of adsorbed intermediates Pt-CO that could produce an enhancement in rates of methanol oxidation.

Compared to bimetallic $\mathrm{Pt} / \mathrm{Ru}$ and $\mathrm{Pt} / \mathrm{Sn}$ catalysts, the $\mathrm{Pt}_{80} \mathrm{Ru}_{10} \mathrm{Sn}_{10}$ ternary nanoparticles exhibit enhanced catalytic activity toward both methanol and ethanol electrooxidation.

The cyclic voltammograms of Figure 2 show the electro-oxidation of methanol, ethanol, acetaldehyde, and acetic acid on BDD-supported $\mathrm{Pt}_{80} \mathrm{Ru}_{10} \mathrm{Sn}_{10}$ nanoparticles recorded at $20 \mathrm{mV} \mathrm{s}^{-1}$ in $1 \mathrm{M} \mathrm{HClO}_{4}+0.1 \mathrm{M}$ electroactive species solutions. Although the ethanol oxidation began at lower potentials than the methanol oxidation, the specific molar current reached a high value for the latter fuel (Figure 2(a)).

The cyclic voltammograms relative to acetic acid and acetaldehyde electro-oxidation (Figure 2(b)) showed that the electrocatalytic activity of ternary nanoparticles toward oxidation of any of these potential intermediates of ethanol oxidation was negligible compared to that toward oxidation of ethanol itself. As a result, the complete oxidation of ethanol was less efficient than the methanol oxidation due to its apparent inability to activate the $\mathrm{C}-\mathrm{C}$ bond scission. Hence, electro-oxidation of ethanol with ternary $\mathrm{Pt}_{80} \mathrm{Ru}_{10} \mathrm{Sn}_{10}$ catalyst was stopped at the formation of $\mathrm{C}_{2}$ oxidation products (acetaldehyde and/or acetic acid). The $\mathrm{Pt}_{80} \mathrm{Ru}_{10} \mathrm{Sn}_{10}$ ternary catalyst did not exhibit any chemical shift of the XPS Pt $4 \mathrm{f}_{7 / 2}$ line compared to that of pure Pt catalyst, indicating no electronic transfer involving Pt. A possible electronic transfer, between $\mathrm{Sn}$ and $\mathrm{Ru}$, may create a new and specific ${ }^{\circ} \mathrm{OH}$ state, weakly adsorbed on $\mathrm{Ru}$ and of higher mobility and reactivity. This new ${ }^{\circ} \mathrm{OH}$ state could well explain the lowered onset potential of alcohol oxidation [23].

2.2. Thermal Deposition. The thermal decomposition of appropriate precursors that have been dissolved in suitable solvents and spread on a metallic support [24] has been

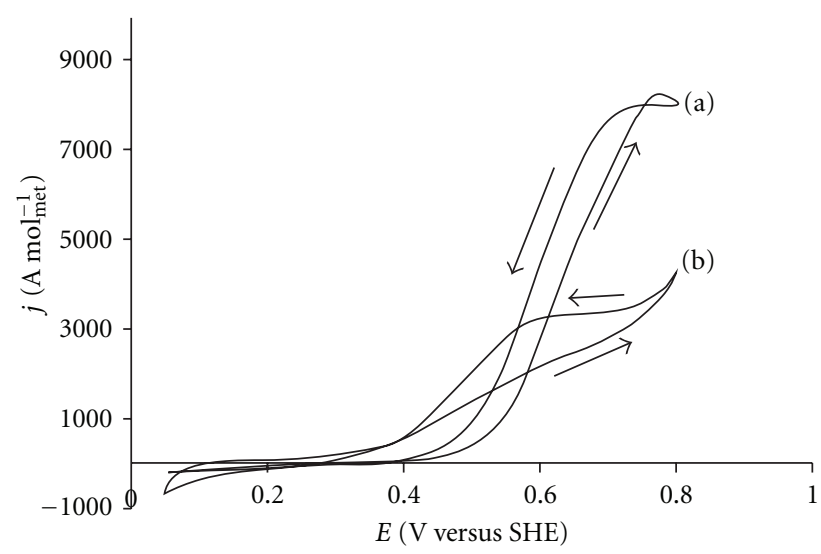

(a)

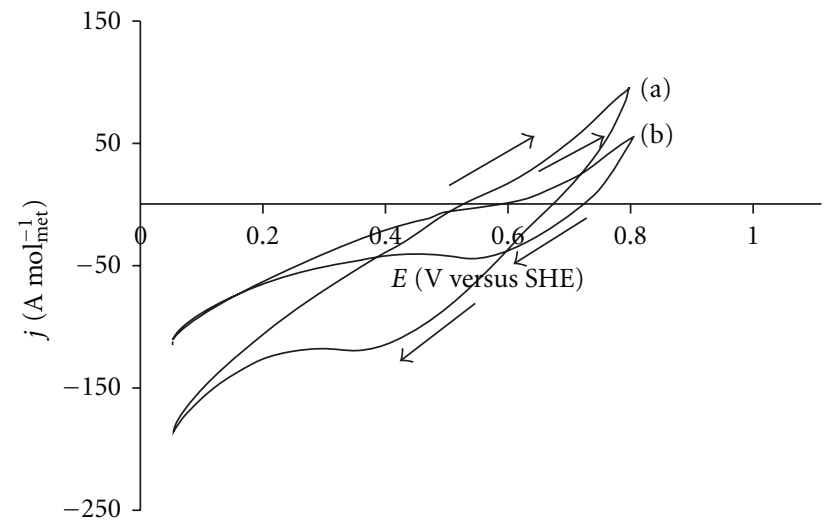

(b)

Figure 2: (a) Cyclic voltammograms of (a) methanol and (b) ethanol electro-oxidation at BDD-supported $\mathrm{Pt}_{80} \mathrm{Ru}_{10} \mathrm{Sn}_{10}$ nanoparticles. (b) Cyclic voltammograms of (c) acetaldehyde, and (d) acetic acid electro-oxidation at $\mathrm{BDD}$-supported $\mathrm{Pt}_{80} \mathrm{Ru}_{10} \mathrm{Sn}_{10}$ nanoparticles. Scan rate of $20 \mathrm{mV} \mathrm{s}^{-1}$ in $1 \mathrm{M} \mathrm{HClO}_{4}+0.1 \mathrm{M}$ electroactive species solutions, $T=25^{\circ} \mathrm{C}$ (Reprinted with permission from [23]).

applied to deposit iridium oxide [21, 25], gold [21, 26], and platinum nanoparticles [27] onto BDD films. The nature of the precursor and the decomposition temperature must be controlled during the procedure since these parameters affect the particle size, nonstoichiometry, and morphology of the oxide layer. The goal of the modification of doped diamond with $\mathrm{IrO}_{2}$, Au, or Pt nanoparticles was to produce electrodes with the well-known properties of iridium oxide, gold or platinum electrodes by using only very low amounts of these precious metals. However, long-term stability is not sufficient at the current state of development.

Siné et al. [21] deposited $\mathrm{IrO}_{2}$ onto BDD film electrode using as precursor $\mathrm{H}_{2} \mathrm{IrCl}_{6}$ at different precursor concentrations, in order to vary the amount of deposited $\mathrm{IrO}_{2}$. The calcinations were performed at $450^{\circ} \mathrm{C}$. At low $\mathrm{IrO}_{2}$ loading, isolated $\mathrm{IrO}_{2}$ particles had a size of about $2-3 \mathrm{~nm}$ and were concentrated at the grain boundaries of the diamond crystals. At higher $\mathrm{IrO}_{2}$ loading, the particles were larger $(10 \mathrm{~nm})$ and their concentration at the grain boundaries of 
the diamond crystals was significantly higher. The voltammetric curves obtained with $\mathrm{BDD}-\mathrm{IrO}_{2}$ electrodes provided a fingerprint of electrode surface transitions occurring during the potential scan. The high capacitive current showed by the $\mathrm{BDD}-\mathrm{IrO}_{2}$ electrode was related to changes in the oxidation state of the $\mathrm{IrO}_{2}$ surface during the potential scan (i.e., $\operatorname{Ir}(\mathrm{III}) / \mathrm{Ir}(\mathrm{II})$ and $\operatorname{Ir}(\mathrm{IV}) / \operatorname{Ir}(\mathrm{III}))$ at 0.4 and $0.95 \mathrm{~V}$, respectively. The very low currents recorded at a BDD electrode were certainly related to the absence of electroactive surface functionalities on the electrode surfaces.

The effect of $\mathrm{IrO}_{2}$ particles deposited on diamond on the oxygen evolution reaction (OER), an inner-sphere reaction, was investigated by $\mathrm{CV}$ performed in $0.5 \mathrm{M} \mathrm{H}_{2} \mathrm{SO}_{4}$. A potential shift of almost $1 \mathrm{~V}$ was noticed between BDD and BDD$\mathrm{IrO}_{2}$ electrodes (Figure 3). At bare diamond, the process took place at very high overpotentials while at $\mathrm{BDD}-\mathrm{IrO}_{2}$, oxygen evolution took place at $1.45 \mathrm{~V}$, close to the equilibrium potential of the redox system $\operatorname{Ir}(\mathrm{VI}) / \operatorname{Ir}(\mathrm{IV})(1.35 \mathrm{~V})$. The current increased sharply at the OER potential, indicating a high electrocatalytic activity of $\mathrm{BDD}-\mathrm{IrO}_{2}$ electrodes. The behavior of the $\mathrm{BDD}-\mathrm{IrO}_{2}$ electrodes can be interpreted entirely as that of $\mathrm{IrO}_{2}$ continuous-film electrodes. Diamond merely acts as an inert substrate on which the catalytic activity of deposited $\mathrm{IrO}_{2}$ particles can be investigated without interference.

On the other hand, platinum particles were deposited on $\mathrm{p}-\mathrm{Si} / \mathrm{BDD}$ substrate by thermal decomposition procedure [27]. The reaction of methanol oxidation in acidic media was used as reaction test of the prepared $\mathrm{p}-\mathrm{Si} / \mathrm{BDD} / \mathrm{Pt}$ electrode. This method consisted in the application of $5 \mu \mathrm{L}$ of a platinum precursor solution $\left(0.2-3 \mathrm{mM} \mathrm{H}_{2} \mathrm{PtCl}_{6}\right.$ in 2-propanol) on the diamond surface $\left(1 \mathrm{~cm}^{2}\right)$, evaporation of the solvent at $60^{\circ} \mathrm{C}$ during $5 \mathrm{~min}$, and finally, thermal decomposition of the precursor by treatment in an oven at $350^{\circ} \mathrm{C}$ during $1 \mathrm{~h}$.

Irregular distribution of platinum clusters (around $3 \mu \mathrm{m}$ ) on the diamond surface was observed in this study. The agglomeration of the Pt particles was related to the inhomogeneity of the interfacial surface tension of the BDD support.

The stability of the deposits was tested by cycling between oxygen and hydrogen evolution reactions. After 500 cycles at $50 \mathrm{mV} \mathrm{s}^{-1}$ the obtained cyclic voltammogram did not show the characteristic peaks for the formation and reduction of the platinum oxide. Furthermore, the SEM images obtained after this treatment showed the absence of platinum particles on the diamond surface. These facts indicated the dissolution/detachment of the platinum by the potential cycling. Therefore, the authors concluded that thermal decomposition procedure was not a suitable method to obtain a well-dispersed and electrochemically stable nanoparticle catalyst.

2.3. Electrodeposition. The electrodeposition is one of the most widely used methods for the preparation and deposition of particles on BDD. As an electroanalytical tool, BDD has been used in the detection of numerous analytes, but it has also been successfully employed as an inert substrate for catalytically active metals and metal oxides $[28,29]$. The

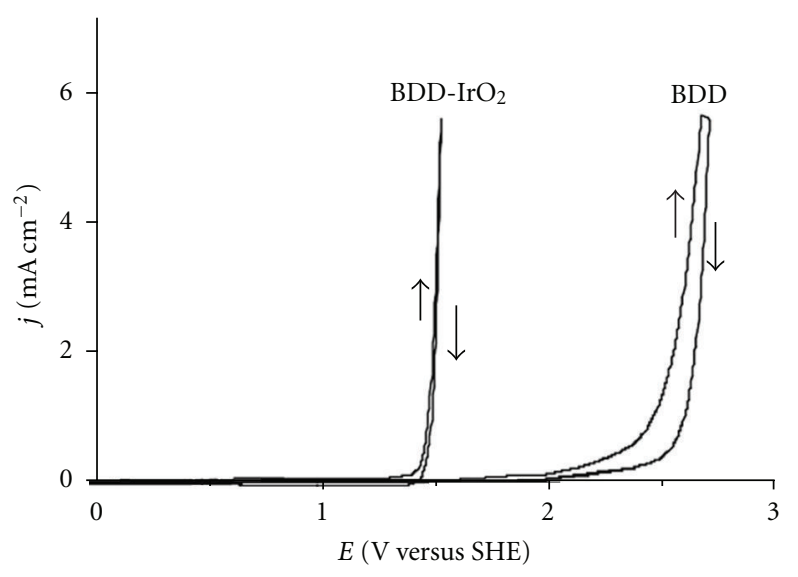

FIgure 3: Cyclic voltammograms recorded at BDD and BDD$\mathrm{IrO}_{2}(G=6.4)$ electrodes in $0.5 \mathrm{M} \mathrm{H}_{2} \mathrm{SO}_{4}$. Scan rate: $100 \mathrm{mV} \mathrm{s}^{-1}$. Geometric surface area $1 \mathrm{~cm}^{2}$. $G=1$ corresponds to $10^{15}$ molecules $\mathrm{IrO}_{2} \mathrm{~cm}^{-2}$ (reprinted with permission from [21]).

modification of a BDD electrode surface has been reported for a limited range of metal nanoparticles, including $\mathrm{Ag}, \mathrm{Au}$, $\mathrm{Pt}, \mathrm{Pd}, \mathrm{Cu}, \mathrm{Bi}, \mathrm{Ni}, \mathrm{Hg}, \mathrm{Pb}, \mathrm{Co}, \mathrm{Ir}, \mathrm{Ru}, \mathrm{Te}, \mathrm{Ti}$, and $\mathrm{Fe}$ [30-32].

One important feature of the BDD electrode is the nonuniform electroactivity across its surface. This is due to the boron doped nature of the polycrystalline diamond, leading to areas of increased reactivity depending on the concentration of B atoms, which are present in an approximate ratio of 1 boron atom to 1000 carbon atoms [33]. Increased activity at the diamond grain boundaries is a feature suggested by the SEM images of polished polycrystalline high quality $\mathrm{BDD}$ surfaces $[34,35]$, and varied local reactivity has also been reported via confocal Raman imaging, photoluminescence [36] and AC impedance experiments $[37,38]$. As such BDD is an excellent electrode material to promote the formation of nanoparticles as opposed to films. Nanoparticles are well known to be ideal for use in catalysis owing to their high surface area to volume ratio and often improved catalytic behavior due to their changed properties from the corresponding bulk material [39].

The advantages of electrodeposition include the fact that most compound semiconductor is obtained at or near room temperature, which is considered low temperature deposition. Electrodeposition also promotes controlled growth and it is generally a low cost methodology when compared to the dry methods. The deposition and co-deposition of the different metals on diamond films have been the most studied systems due to their high interest in electrocatalysis. Deposits in BDD received great attention due to their applicability in fuel cell systems, the methanol oxidation with being the preferred test reaction [40].

As $\mathrm{Pt}$ is one of the more deposited metals by electrodeposition technique, the electrodeposition of $\mathrm{Pt}$ particles on a $\mathrm{BDD}$ electrode is generally performed by applying a potential step to a deaerated $2 \mathrm{mM} \mathrm{H}_{2} \mathrm{PtCl}_{6}$ solution in $1 \mathrm{M} \mathrm{HClO}_{4}$ [27]. The potential is shifted from an equilibrium potential ( $1 \mathrm{~V}$, where no reduction of platinic ions takes place) to 


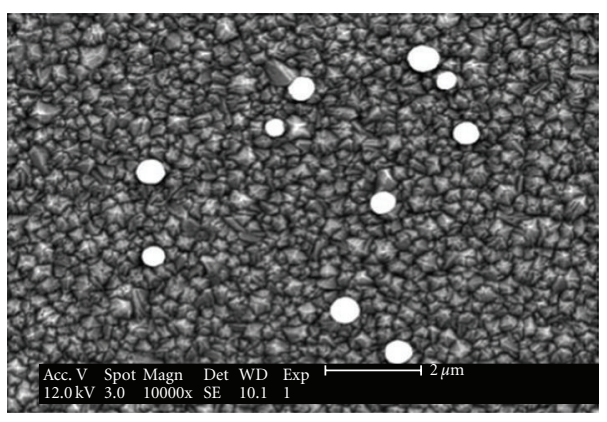

(a)

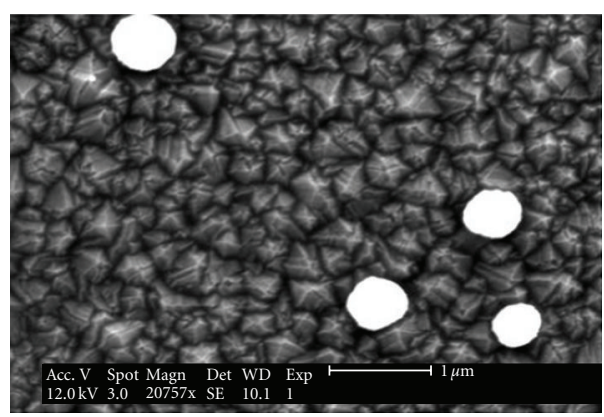

(b)

FIGURE 4: SEM images at two different magnification scales of a BDD-Pt electrode prepared by electrodeposition with a single potential step (5 s) from 1 to $0.02 \mathrm{~V}$ in a $\mathrm{N}_{2}$-saturated $2 \mathrm{mM} \mathrm{H}_{2} \mathrm{PtCl}_{6}+1 \mathrm{M} \mathrm{HClO}_{4}$ solution (reprinted with permission from [21]).

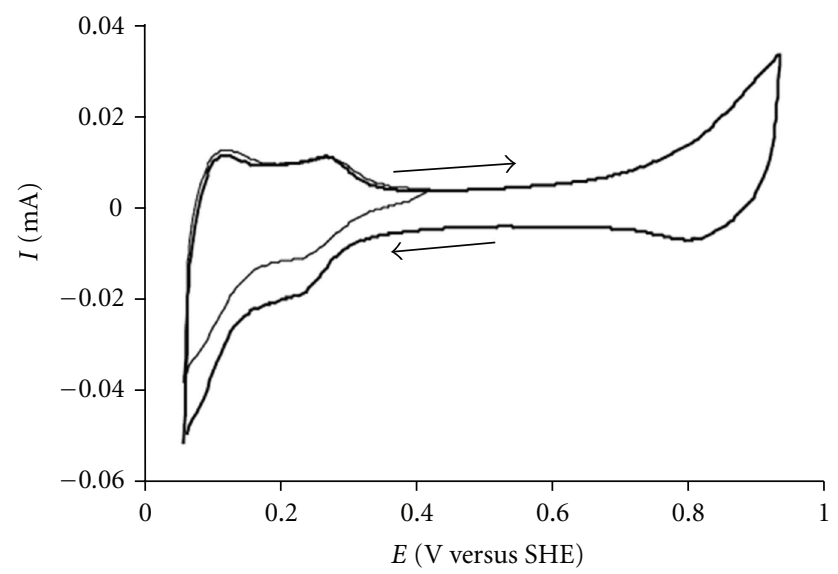

Figure 5: Cyclic voltammograms of electrodeposited Pt particles on BDD electrode. Recorded in a $\mathrm{N}_{2}$-saturated $1 \mathrm{M} \mathrm{HClO}_{4}$ solution at $50 \mathrm{mV} \mathrm{s}^{-1}$ and $25^{\circ} \mathrm{C}$. Conditions of electrodeposition: single potential step ( $5 \mathrm{~s}$ ) from 1 to $0.02 \mathrm{~V}$ in a $\mathrm{N}_{2}$-saturated $2 \mathrm{mM} \mathrm{H}_{2} \mathrm{PtCl}_{6}$ $+1 \mathrm{M} \mathrm{HClO}_{4}$ solution (reprinted with permission from [21]).

a potential at which the reduction of $\mathrm{Pt}^{4+}$ to metallic $\mathrm{Pt}$ occurs $(0.02-0.15 \mathrm{~V})$. The electrodeposition mechanism was studied by multistep chronoamperometry.

Montilla et al. [27] showed that the electrodeposition of $\mathrm{Pt}$ on BDD film electrodes follows a mechanism of progressive nucleation, which favors a higher dispersion of the platinum particles, increasing the amount of new nuclei for Pt deposition on the BDD support. The stability of the electrochemically deposited electrodes was tested by cycling the potential (1000 cycles) between oxygen and hydrogen evolution reactions in a $0.5 \mathrm{M} \mathrm{H}_{2} \mathrm{SO}_{4}$ solution at a sweep rate of $50 \mathrm{mV} \mathrm{s}^{-1}$. This treatment resulted in a dissolution/detachment of an important fraction of the deposited $\mathrm{Pt}$, since the amount of Pt presents on the electrode surface (estimated from the electrical charge in the cyclic voltammograms) after the potential cycling was reduced by approximately $65 \%$ with respect to the initial conditions.

The most important techniques for characterization of electrodeposits on BDD are SEM, XRD, energy-dispersive $\mathrm{X}$-ray spectroscopy (EDS), atomic force microscopy (AFM),
Raman spectroscopy, scanning electrochemical microscopy (SECM), XPS, and CV. Figure 4 shows SEM micrographs of a BDD-Pt electrode prepared by performing a potential step from $1 \mathrm{~V}$ to $0.02 \mathrm{~V}$ in a $2 \mathrm{mM} \mathrm{H}_{2} \mathrm{PtCl}_{6}+1 \mathrm{M} \mathrm{HClO}_{4}$ solution for $5 \mathrm{~s}$ [21]. Spherical and isolated particles are observed with a quite large size variation that covers the $40-700 \mathrm{~nm}$ range. This is indicative of continuous formation of new nuclei during deposition and it is in agreement with the progressive mechanism of nucleation of Pt on BDD.

A typical CV for electrodeposited Pt particles on BDD is shown in Figure 5 [21]. This voltammogram exhibits the characteristic feature of $\mathrm{Pt}$, that is, two distinctive $\mathrm{H}$ adsorption-desorption peaks between 0.05 and $0.35 \mathrm{~V}$, followed by a fine double layer region corresponding to metallic Pt. The electrochemical response of this BDDPt composite electrode can be attributed solely to the deposited Pt particles-even at very low Pt loadings, due to the chemical inertness and low background current of the diamond substrate. This justifies the choice of BDD for the electrochemical study of supported catalytic nanoparticles.

Although electrodeposited $\mathrm{Pt}$ particles on BDD are efficient for methanol electro-oxidation, their size domain is so broad that they cannot be strictly classified as nanoparticles. The literature attributes this heterodispersity to the inhomogeneous nature of the BDD substrates [41], mainly to the presence of nondiamond $\mathrm{sp}^{2}$ impurities that act as preferential deposition sites. Therefore, a "size effect" cannot be reasonably expected in this case, and some alternative synthesis techniques have to be employed to deposit real $\mathrm{Pt}$ nanoparticles on BDD.

The Pt-Ru binary metallic catalyst is commonly accepted as the best electrocatalyst for methanol oxidation. The fundamental mechanism studies for Pt-Ru catalysts indicate that methanol is oxidized according to bifunctional mechanism [42]. Surface-sited Pt atoms oxidatively dehydrogenate the chemisorbed methyl moiety in consecutive steps to yield a residual Pt-CO fragment that cannot be oxidized to $\mathrm{CO}_{2}$ at direct methanol fuel cell potentials. Pt adsorbed $\mathrm{CO}$ is removed via an oxygen-transfer step from electrogenerated $\mathrm{Ru}-\mathrm{OH}$. $\mathrm{Ru}$ transfers oxygen more effectively than $\mathrm{Pt}$ due to its ability to oxidatively absorb water at less positive potentials [43]. 


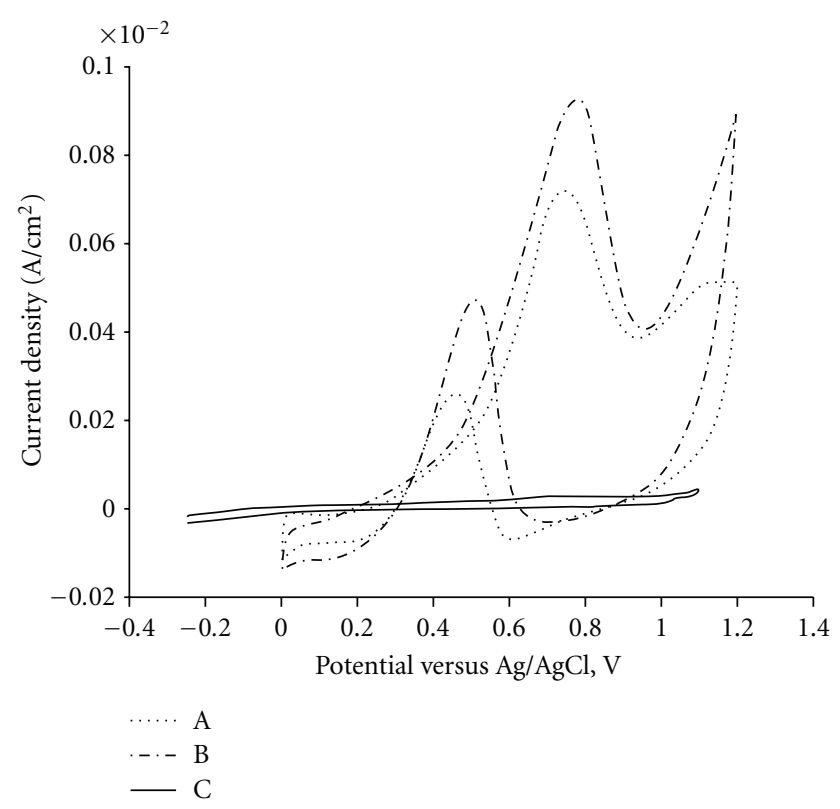

Figure 6: Study of cyclic voltammetry of diamond films with electrocatalyst deposition on $0.1 \mathrm{MeOH} / 0.5 \mathrm{~m} \mathrm{H}_{2} \mathrm{SO}_{4}$ at $50 \mathrm{mV} \mathrm{s}^{-1}$ : (A) $\mathrm{Pt} / \mathrm{BDD}$, (B) $\mathrm{Pt}-\mathrm{Ru} / \mathrm{BDD}$, and (C) BDD (reprinted with permission from [44]).

In this sense, polycrystalline $\mathrm{BDD}$ films were proposed by González-González et al. [44] as the alternative material to obtain high-area carbon supports using electrodeposition, with potential application for direct methanol fuel cell electrocatalysts. The electrocatalytical behavior of $\mathrm{Pt} / \mathrm{BDD}$, $\mathrm{Pt}-\mathrm{Ru} / \mathrm{BDD}$ and BDD electrodes towards the oxidation of methanol in acidic media was evaluated by CV in Figure 6 . Thus, the maximum current densities obtained for methanol oxidation were about $0.73 \mathrm{~mA} \mathrm{~cm}^{-2}$ for Pt and $0.94 \mathrm{~mA} \mathrm{~cm}^{-2}$ for Pt-Ru deposited on BDD. However, as indicated by the authors, the fact that $\mathrm{Pt}-\mathrm{Ru}$ exhibited lower potentials than Pt may be expected in the basis of previous studies [42]; nevertheless, more investigation is necessary to completely understand the composition and particle size effects.

The electrodeposition of $\mathrm{Pt}-\mathrm{Ru}$ electrocatalytic particles was recently studied by comparing simultaneous and sequential deposition on BDD supports using a potentiostatic method [45]. Smooth cluster morphologies were observed for simultaneous deposition and a dendritic structure was observed for sequential deposition from SEM studies (Figure 7). The morphology of sequential deposition was dominated by Pt deposition in the first step, while a change of aggregate morphology due to the presence of Ru was observed for simultaneous deposition. This different morphology and microstructure contributed to different electrochemical performance.

$\mathrm{Pt}-\mathrm{Ru}$ deposits from simultaneous deposition showed stable cyclic voltammograms in sulfuric acid, in contrast to the severe dissolution of Ru which was seen for the deposits from sequential deposition.

An enhanced electrocatalytic performance for the oxidation of methanol was observed for binary Pt-Ru deposits from both sequential and simultaneous deposition, in comparison to that seen on pure $\mathrm{Pt}$, both in terms of onset potential and current density for methanol oxidation. Compared to sequential deposition, Pt-Ru electrocatalysts from simultaneous deposition exhibited higher activity and more tolerance to $\mathrm{CO}$ poisoning for methanol oxidization, and this could be further optimized by choice of the electrodeposition potential. The best catalytic performance was obtained at $\mathrm{Pt} / \mathrm{Ru}$ ratio of around 0.3 in used experimental conditions. Differing rate-determining steps were identified from Tafel plots for methanol oxidization for the different catalysts (Figure 8).

The Tafel curves of simultaneously deposited $\mathrm{Pt} / \mathrm{Ru}$ had the same slope of around $173 \mathrm{mV} / \mathrm{dec}$, indicating that the dehydrogenation of methanol molecules was very fast at even relatively low overpotential and the first rate-determining step was the migration of $\mathrm{CO}_{\mathrm{ads}}$ between $\mathrm{Pt}$ sites and $\mathrm{Ru}$ sites [46]. However, the Tafel plot of sequential deposited $\mathrm{Pt}-\mathrm{Ru}$ presented two linear regions: a slope of around $115 \mathrm{mV} / \mathrm{dec}$ in the first region below $0.45 \mathrm{~V}$ which indicated a rate-determining step of dehydrogenation of methanol molecules, and a slope of around $289 \mathrm{mV} / \mathrm{dec}$ in the second region above $0.45 \mathrm{~V}$; indicating a change of rate-determining step to the oxidation of CO like absorbents on catalytic surfaces [47]. The differing Tafel plots and rate-limiting steps highlighted how subtle changes in the properties of the Pt-Ru particles could significantly influence catalytic properties and performance.

In a different approach, $\mathrm{Pt} / \mathrm{BDD}$ powder electrocatalyst was prepared via electrochemical deposition of platinum, and the electrochemical behavior was compared with that for $\mathrm{Pt} /$ graphite powder [48]. The conductive diamond powder (particle size range, less than $150 \mu \mathrm{m}$ ) was obtained from the Element Six Co and used as support for the Pt deposition. Initially a small amount (e.g., $50 \mathrm{mg}$ ) of BDD powder was preheated at $110^{\circ} \mathrm{C}$ in air and then poured into $5 \mathrm{~mL}$ of warm $\mathrm{H}_{2} \mathrm{PtCl}_{6}$ solution $(10 \mathrm{mM})$ in ethanol. The suspension was blended for $30 \mathrm{~min}$ in an ultrasonic bath, and then the solvent was evaporated under continuous stirring. After further drying at $110^{\circ} \mathrm{C}$, the resulting agglomerates were ground in an agate mortar. Secondly, the deposition of platinum was performed by continuously cycling the potential of the coated electrodes $\left(20 \mathrm{mV} \mathrm{s}^{-1}\right)$ within the potential range 0.5 to $-0.2 \mathrm{~V}$ in a nitrogen-saturated $0.5 \mathrm{M} \mathrm{H}_{2} \mathrm{SO}_{4}$ solution. Cyclic voltammograms were recorded, and the deposition process was continued until a stable voltammetric response was obtained (typically, after $c a$. 30 cycles).

The results of the steady state and long-time polarization measurements suggested that, when deposited on conductive diamond powder, platinum may be slightly less susceptible to deactivation, for example, via $\mathrm{CO}$ poisoning, during methanol oxidation. This behavior was ascribed to the increased hydrophilicity of the oxidized diamond, to a possible electronic effect of the oxygen-terminated support, or to the absence of the adsorption of reaction intermediates that could foul the Pt surface. The finding of this study could indicate that by using BDD powder as a support, it is possible to minimize the loading of alloying metals such as ruthenium, while maintaining high catalytic activity. 


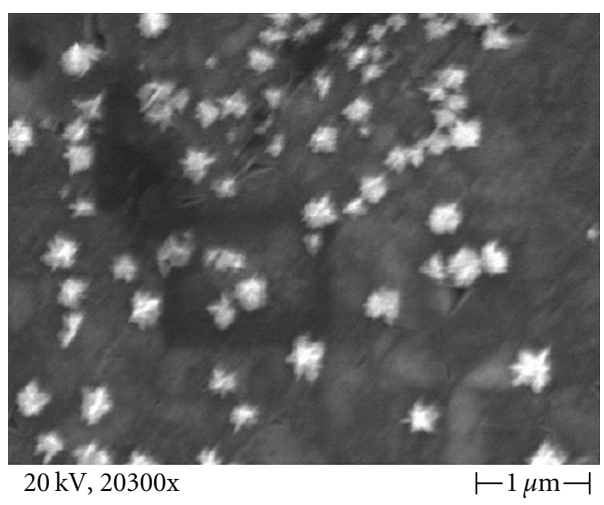

(a)

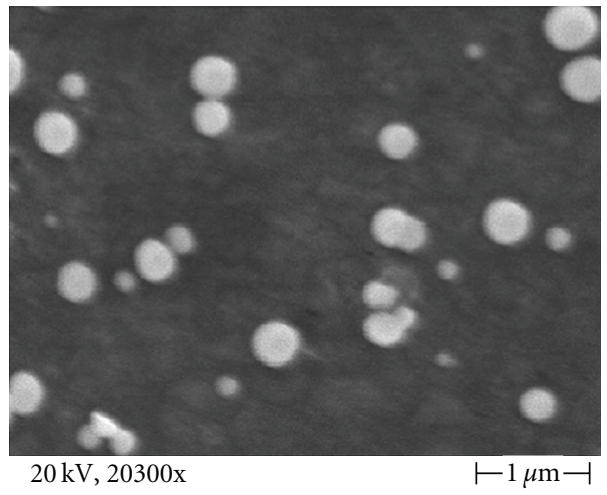

(b)

FIGURE 7: SEM images of Pt-Ru deposited on BDD electrode at $-0.2 \mathrm{~V}$ for $10 \mathrm{~min}$, (a) sequential deposition, and (b) simultaneous deposition (reprinted with permission from [45]).

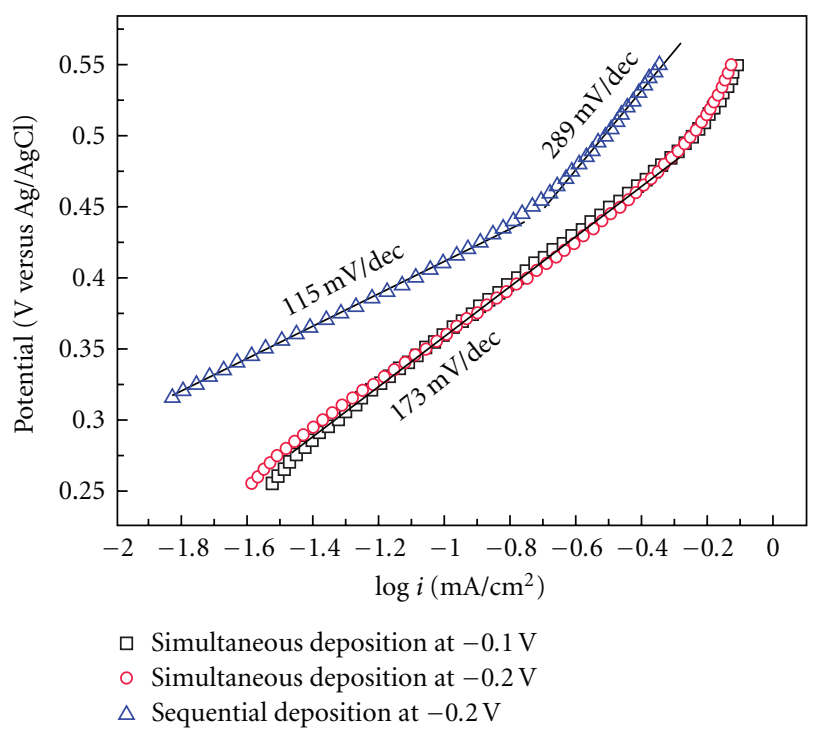

Figure 8: Tafel plots of anode polarization curve in 1.0 M methanol and $0.5 \mathrm{M} \mathrm{H}_{2} \mathrm{SO}_{4}$ solution for $(\square)$ simultaneous deposition at $-0.1 \mathrm{~V},(\circ)$ simultaneous deposition at $-0.2 \mathrm{~V}$, and $(\triangle)$ sequential deposition at $-0.2 \mathrm{~V}$ (reprinted with permission from [45]).

2.4. Sol-Gel Method. Surface modifications of BDD electrodes have been carried out with several metal oxides and some mixed composites using the sol-gel method $[49,50]$. It is well known that sol-gel technique is a suitable process for coating substrates for energy storage materials and electrochemical devices; in either case, there are many interfaces between components and many components that have to perform reliably and safely. There are interfaces between electrodes and current collectors, between electrodes and electrolyte and between electrodes and interconnects. In some cases, the interfaces are the location of failure in an operating fuel cell and problems due to chemical reactions and increased contact resistance can occur. Also, elevated temperatures lead to microstructure changes, crystallization, thermal expansion mismatch, and delamination. In these complicated materials systems, the use of sol-gel processing is well suited to the need for accurate placement of critical materials [51].

The sol-gel method starts with a solution consisting of metal compounds, such as metal alkoxides, and acetylacetonates as source of oxides, water as hydrolysis agent, alcohol as solvent, and acid or base as catalyst. Metal compounds undergo hydrolysis and polycondensation at room temperature, giving rise to sol, in which polymers or fine particles are dispersed. Further reaction connects the particles, solidifying the sol into wet gel, which still contains water and solvents. Vaporization of water and solvents produces a dry gel (xerogel), an aerogel results from a supercritical drying process. Heating gels to several hundred degrees produces dense oxides as products. Coating films can be made by dip-coating or spin-coating of the sol. Unsupported films can be made by synthesizing the film at the interface between alkoxide solution and water. Membranes are prepared by pouring the sol on the porous oxide with coarse pores. Particles with sharp size distribution can be precipitated and grown in the sol [52].

The advantages of sol-gel technique in the preparation of ceramics include better homogeneity, lower temperature processing, and more uniform phase distribution in multicomponent systems, easy preparation of thin films and coatings, better size and morphological control in powder synthesis and opportunities for the preparation of new crystalline and noncrystalline solids [53]. The main factors that are important in development of thin films are the uniformity and thickness of film, its adhesion to the substrate, and resistance to cracking. In this context, some research groups are working on the BDD surface modification by sol-gel technique for different catalytic coatings such as metallic oxides $\left(\mathrm{MO}_{2}, \mathrm{M}=\mathrm{Pb}, \mathrm{Ru}\right.$, and Ir) [49] or metal catalyst like platinum.

Suffredini et al. [54] reported the preparation of $\mathrm{Pt}$ $\mathrm{RuO}_{2}$ deposits on a carbon black substrate using the sol-gel method; their activity toward methanol electrooxidation was investigated and they found superior activity of the $\mathrm{Pt}-\mathrm{RuO}_{2} / \mathrm{C}$ anodes prepared by sol-gel than those of 


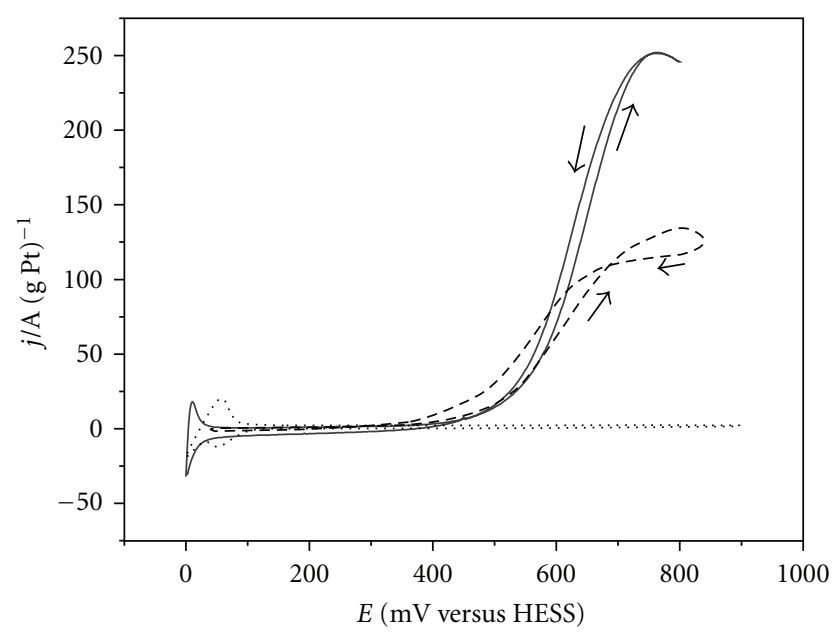

(a)

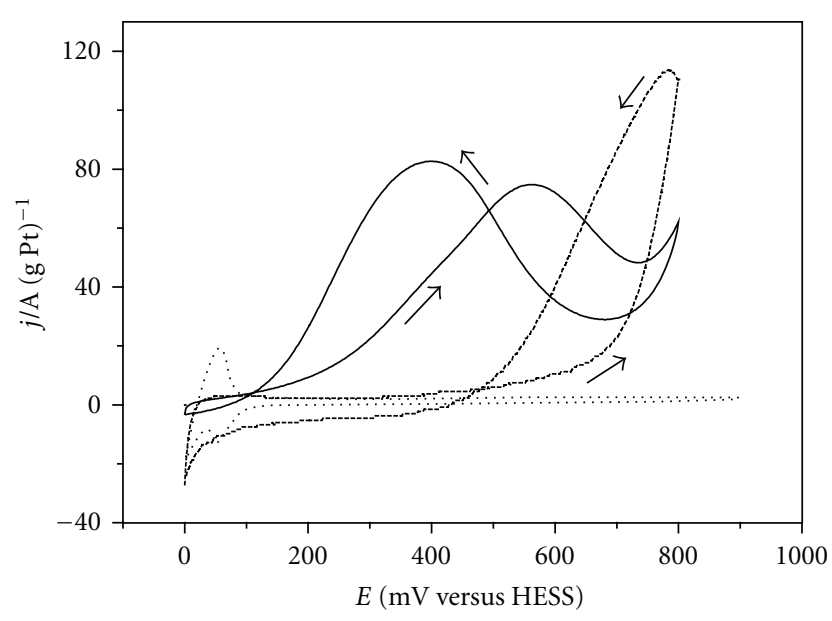

(b)

Figure 9: Voltammetric oxidation of $1.0 \mathrm{M}$ of methanol (a) and ethanol (b) in $0.5 \mathrm{M} \mathrm{H}_{2} \mathrm{SO}_{4}$ on Pt-RuO$/ 2$ (full lines) and Pt/C (traced lines) composites fixed on BDD surfaces. Baselines (dotted lines) were included as a comparison. Scan rate $\nu=10 \mathrm{mV} \mathrm{s}^{-1}$ (reprinted with permission from [50]).

similar composition but prepared by alternative methods. Later, Suffredini et al. [50] reported the electro-oxidation of methanol and ethanol using a $\mathrm{Pt}-\mathrm{RuO}_{2} / \mathrm{C}$ composite prepared by sol-gel method supported on $\mathrm{BDD}$ which were evaluated by $\mathrm{CV}$. Catalytic properties of Pt- $\mathrm{RuO}_{2} / \mathrm{C}$ supported over BDD were evaluated by means of cyclic voltammetric technique. In this context, electrochemical assays were also conducted using a glassy carbon (GC) electrode as the substrate for the composite. The capacitance in the potential window $100-400 \mathrm{mV}$ versus HESS using a GC electrode was $1.26 \times 10^{-5} \mathrm{C}$ which was considerably larger than that calculated at $\mathrm{BDD}$ (i.e., $2.69 \times 10^{-6} \mathrm{C}$ ), indicating that $\mathrm{BDD}$ can be used as substrate with lower substrate interferences than GC. The potential region of methanol oxidation for forward and reverse scans as well as for the peak showed that the $\mathrm{Pt}-\mathrm{RuO}_{2} / \mathrm{C}$ composite on the BDD substrate presented a higher current density than the composite supported on GC electrode. In this frame, the authors emphasized an interesting difference between the two voltammograms, indicating that the forward and backward lines of BDD substrate were almost coincident while a large difference was observed for GC electrode. However, other tests using the same $\mathrm{Pt}-\mathrm{RuO}_{2} / \mathrm{C}$ material, indicating that the differences should be attributed to the substrate and that probably reflect the great capacitive effect of the GC.

In light of this discussion, the most important contribution to the larger oxidation currents was that the use of BDD surfaces practically avoids the substrate contribution and thus, the response of electrode was only dependent on the catalyst. Results presented in Figures 9(a) and 9(b) correspond to methanol and ethanol oxidation responses, respectively, for $\mathrm{Pt}-\mathrm{RuO}_{2} / \mathrm{C}$ catalyst over $\mathrm{BDD}$ studied by $\mathrm{CV}$ at $10 \mathrm{mV} \mathrm{s}^{-1}$. As well, they included in this figure the responses of a commercial 10\% $\mathrm{Pt} / \mathrm{C}$ catalyst on $\mathrm{BDD}$ as a comparison. As observed in Figure 9(a), the oxidation of methanol started at $380 \mathrm{mV}$ versus HESS on both substrates and these results were in agreement with the data reported by $\mathrm{He}$ et al. [43] where Pt-Ru nanoparticles were electrodeposited on carbon nanotubes. For the case of ethanol oxidation (Figure 9(b)), the electrochemical responses were extremely different for both cases, showing the presence of a reactivation process on the catalyst surface, but in the case of Pt- $\mathrm{RuO}_{2} / \mathrm{C}$ material, the onset potential of the ethanol oxidation was much lower than for the $\mathrm{Pt} / \mathrm{C}$. However, the response in current density for $\mathrm{Pt}-\mathrm{RuO}_{2} / \mathrm{C}$ material was fairly large for an extended potential window, indicating a multistep processes during ethanol oxidation.

The composite catalysts $\mathrm{Pt}-\mathrm{PbO}_{x} / \mathrm{C}, \mathrm{Pt}-\mathrm{IrO}_{2} / \mathrm{C}$, Pt$\left(\mathrm{RuO}_{2}-\mathrm{IrO}_{2}\right) / \mathrm{C}, \mathrm{Pt}-\left(\mathrm{RuO}_{2}-\mathrm{PbO}_{x}\right) / \mathrm{C}$, and $\mathrm{Pt}-\left(\mathrm{IrO}_{2}-\mathrm{PbO}_{x}\right) / \mathrm{C}$ were prepared by sol-gel and fixed on BDD substrate to be used as anodes for studies of direct ethanol fuel cells (DEFCs) [55]. The sol-gel method gives as a result the formation of the nanometric crystallite dimensions of the composites which can be responsible for the enhanced catalytic activity toward ethanol oxidation. The $\mathrm{XRD}$ analysis revealed that $\mathrm{Pb}$ was deposited as a mixture of $\mathrm{PbO}$ and $\mathrm{PbO}_{2}$ and the EDX measurements indicated that $\mathrm{Pb}$ is preferentially deposited as compared with Pt.

Quasi-steady-state polarization curves showed that the composites $\mathrm{Pt}-\left(\mathrm{RuO}_{2}-\mathrm{PbO}_{x}\right) / \mathrm{C}$ and $\mathrm{Pt}-\left(\mathrm{RuO}_{2}-\mathrm{IrO}_{2}\right) / \mathrm{C}$ started the oxidation process in very low potentials (155 and $178 \mathrm{mV}$, resp.), presenting good performance to promote the ethanol oxidation. In fact, the composite $\mathrm{Pt}-\left(\mathrm{RuO}_{2}-\right.$ $\left.\mathrm{PbO}_{x}\right) / \mathrm{C}$ presented a gain of about $467 \mathrm{mV}$ in the onset potential as compared to the $\mathrm{Pt} / \mathrm{C}$ composite and, as a consequence, very high currents can be obtained on this catalyst at low potentials. On the contrary, the combination of $\mathrm{IrO}_{2}$ with $\mathrm{PbO}_{x}$ disfavors the catalytic activity for the ethanol oxidation, showing a nonsynergic behavior [55].

These catalysts studied for ethanol oxidation were also tested as anode composites for the oxidation of methanol 


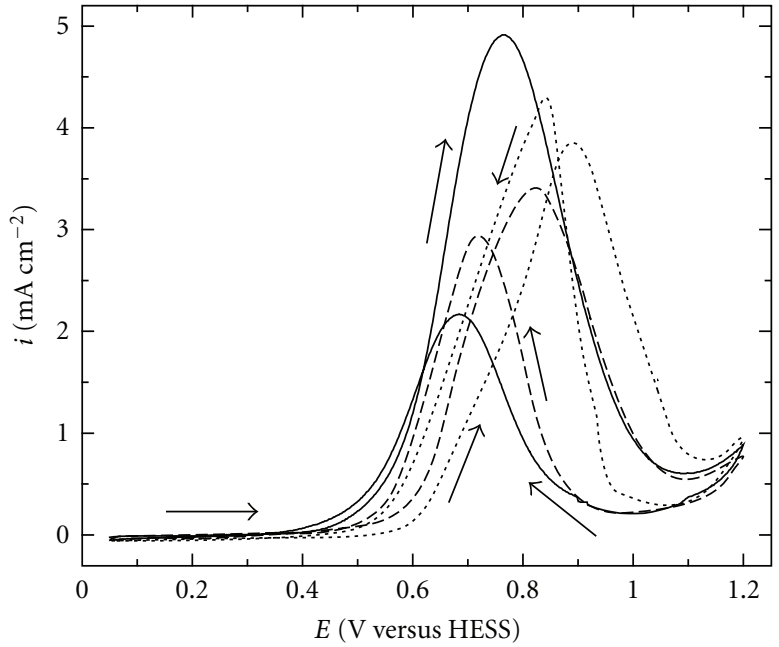

(a)

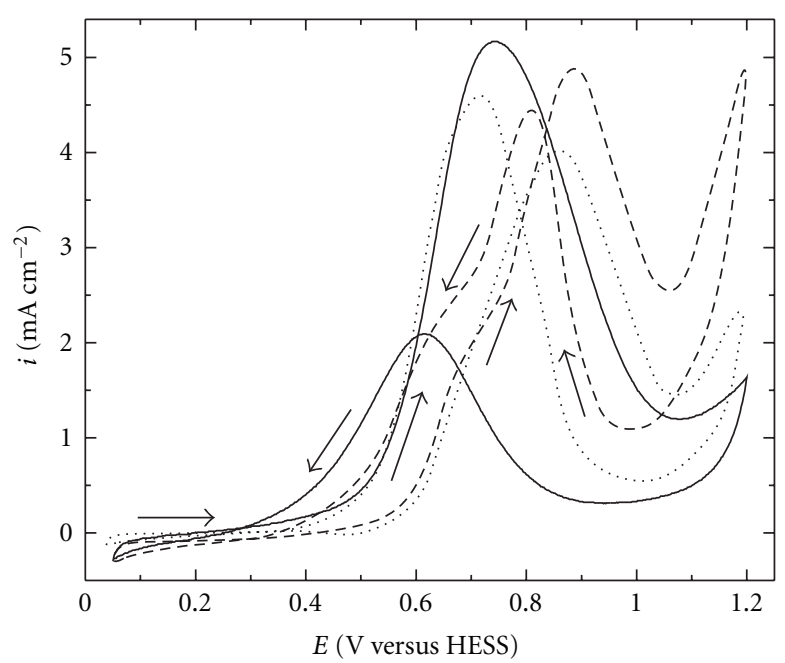

(b)

Figure 10: Cyclic voltammetric study (second cycle) for electrochemistry oxidation of $0.5 \mathrm{M}$ of (a) methanol and (b) ethanol. Dotted line correspond to $\mathrm{Pt} / \mathrm{BDD}$, dashed line $\mathrm{Pt}-\mathrm{RuO}_{2} / \mathrm{BDD}$, and solid line $\mathrm{Pt}-\mathrm{RuO}_{2}-\mathrm{RhO}_{2} / \mathrm{BDD}$ electrodes materials $\left(\nu=0.005 \mathrm{~V} \mathrm{~s}{ }^{-1}\right)($ reprinted with permission from [58]).

[56]. CV and quasistationary polarization experiments showed that the new $\mathrm{Pb}$-based catalysts presented good performance to promote the oxidation of methanol in acidic media. Current-time measurements also proved the good performance of the Pt- $\left(\mathrm{RuO}_{2}-\mathrm{PbO}_{x}\right) / \mathrm{C}, \mathrm{Pt}-\mathrm{PbO}_{x}$, and $\mathrm{Pt}-\left(\mathrm{RuO}_{2}-\mathrm{IrO}_{2}\right) / \mathrm{C}$ catalysts to oxidize methanol in acidic media. Therefore, the authors concluded that the addition of metallic $\mathrm{Pt}$ and $\mathrm{PbO}_{x}$ onto high-area carbon powder, by the sol-gel route, constitutes an interesting way to prepare anodes with high catalytic activity for further applications in direct methanol fuel cell systems.

On the other hand, Salazar-Banda et al. [57] carried out the direct deposition of platinum oxide particles $\left(\mathrm{PtO}_{x}\right)$ on BDD surfaces by the sol-gel method and testing several pre- and posttreatments of the surface for electrochemical experiments. They studied the electrochemical stability of the catalytic coatings indicating that the electrodes retained $91.6 \%$ of the coated material after 1000 voltammetric cycles conducted in the water decomposition electrochemical window. Their results demonstrate that the sol-gel method produces more stable $\mathrm{PtO}_{x}$ deposits on BDD surfaces than other reported techniques.

In addition, covering the modified electrode surface $\left(\mathrm{PtO}_{x} / \mathrm{BBD}\right)$ with a Nafion film $(40 \mu \mathrm{L}$ of a $0.5 \%$ Nafion solution evaporated on the electrode surface using a hot air stream) made negligible the clusters detachment/dissolution after the extensive potential cycling test describe above. In another study carried out by Suffredini et al. [49] that used a similar electrode configuration (Pt/BBD + Nafion film), showed that 1000 voltammetric cycles for the ethanol oxidation reaction also left the surface practically unchanged.

In a following study [58] the BDD electrode surface was modified with $\mathrm{Pt}, \mathrm{Pt}-\mathrm{RuO}_{2}, \mathrm{Pt}-\mathrm{RuO}_{2}-\mathrm{RhO}_{2}$ by the sol-gel process to study the oxidation of methanol and ethanol. Each catalyst was deposited as coating film on BDD electrodes, previously pretreated at $400^{\circ} \mathrm{C}$ for $30 \mathrm{~min}$ in air, using as precursors the corresponding metallic acetylacetonates. The solgel solutions were prepared with $\mathrm{Pt}(\mathrm{II}), \mathrm{Ru}(\mathrm{II})$ and $\mathrm{Rh}$ (III) acetylacetonates in a mixture of isopropyl alcohol and acetic acid $(3: 2, \mathrm{v} / \mathrm{v})$ obtaining a $0.01 \mathrm{M}$ as a final concentration of each solution. These solutions were transferred onto BDD surfaces by painting and the solvents were evaporated at $80^{\circ} \mathrm{C}$ for $5 \mathrm{~min}$ in an oven. This procedure was repeated 15 times and finally the electrodes were annealed at $400^{\circ} \mathrm{C}$ for $1 \mathrm{~h}$ in an argon atmosphere.

The physical characterization of the different composite materials deposited on BDD demonstrated that the relatively simple and low-cost sol-gel method is a very useful technique to modify BDD electrodes producing catalysts nanoparticles with a well-controlled atomic composition and a homogeneous distribution on the surface.

The voltammetric responses for bare BDD and BDD after modification with $\mathrm{Pt}, \mathrm{Pt}-\mathrm{RuO} \mathrm{O}_{2}$ and $\mathrm{Pt}-\mathrm{RuO}-\mathrm{RhO}_{2}$, evidenced that the electrochemical potential window was greatly diminished due to the catalytic effect of the deposited metals after modification. Cyclic voltammetric assays were carried out for methanol and ethanol oxidation at a scan rate of $0.005 \mathrm{~V} \mathrm{~s}^{-1}$, in acidic media $\left(\mathrm{H}_{2} \mathrm{SO}_{4}\right)$ adding $0.5 \mathrm{M}$ alcohol concentration; their results are shown in Figure 10. These studies revealed that the CO poisoning effect for both alcohols oxidation reaction was mainly inhibited on the ternary alloy $\mathrm{Pt}-\mathrm{RuO}_{2}-\mathrm{RhO}_{2} / \mathrm{BDD}$ electrode (solid lines in Figure 10) due to the $\mathrm{Rh}$ presence, which promotes a better catalytic effect for these reactions by either prompting the oxidation of the adsorbed intermediate species to $\mathrm{CO}_{2}$ or diminishing the absorption of $\mathrm{CO}$ and the others intermediates over Pt surface.

Moreover, chronoamperometric experiments analyzed by a modified Cottrell's law strongly suggest that poisoning of the surface by $\mathrm{CO}$ is greatly inhibited on the ternary 
TABLE 2: Catalysts or composite catalysts on BDD support synthesized by the sol-gel method.

\begin{tabular}{|c|c|c|c|c|}
\hline Fuel studied & $\begin{array}{l}\text { Catalyst deposited on } \\
\text { BDD electrode }\end{array}$ & $\begin{array}{l}\text { Characterization } \\
\text { techniques }\end{array}$ & Precursors & Reference \\
\hline Methanol and ethanol & $\begin{array}{c}\mathrm{Pt} \\
\mathrm{Pt}-\mathrm{RuO}_{2} \\
\mathrm{Pt}-\mathrm{RuO}_{2}-\mathrm{RhO}_{2} \\
\end{array}$ & $\begin{array}{l}\text { XRD, EDX, } \\
\text { AFM, SEM }\end{array}$ & $\begin{array}{l}\mathrm{Pt}(\mathrm{II}), \mathrm{Ru}(\mathrm{III}), \mathrm{Rh}(\mathrm{III}) \text { acetylacetonates } \\
\text { in a mixture of isopropyl alcohol and } \\
\text { acetic acid }\end{array}$ & {$[58]$} \\
\hline Ethanol & $\begin{array}{c}\mathrm{PtO}_{x} \\
\mathrm{PtO}_{x}-\mathrm{RuO}_{2} \\
\mathrm{RuO}_{2} \\
\mathrm{IrO}_{2} \\
\mathrm{PbO}_{2} \\
\end{array}$ & AFM & $\begin{array}{l}\mathrm{Pt}(\mathrm{II}), \mathrm{Ru}(\mathrm{III}), \mathrm{Pb}(\mathrm{II}), \mathrm{Ir}(\mathrm{III}) \\
\text { acetylacetonates in a mixture of isopropyl } \\
\text { alcohol and acetic acid }\end{array}$ & [49] \\
\hline Methanol and ethanol & $\mathrm{Pt}-\mathrm{RuO}_{2} / \mathrm{C}$ & $\mathrm{XRD}, \mathrm{EDX}$ & $\begin{array}{l}\mathrm{Pt}(\mathrm{II}), \mathrm{Ru}(\mathrm{III}) \text { acetylacetonates in a } \\
\text { mixture of isopropyl alcohol and acetic } \\
\text { acid/carbon black powder (Vulcan } \\
\mathrm{XC72R} \text { ) }\end{array}$ & {$[50]$} \\
\hline Methanol & $\mathrm{Pt}-\mathrm{RuO}_{x}$ & SEM, DRX & $\begin{array}{l}\mathrm{Pt}(\mathrm{II}), \mathrm{Ru}(\mathrm{III}) \text { acetylacetonates in a } \\
\text { mixture of isopropyl alcohol and acetic } \\
\text { acid }\end{array}$ & {$[59]$} \\
\hline Ethanol & $\begin{array}{c}\mathrm{Pt}-\mathrm{RuO}_{2} / \mathrm{C} \\
\mathrm{Pt}-\mathrm{PbO}_{x} / \mathrm{C} \\
\mathrm{Pt}_{-} \mathrm{IrO}_{2} / \mathrm{C} \\
\mathrm{Pt}-\left(\mathrm{RuO}_{2}-\mathrm{IrO}_{2}\right) / \mathrm{C} \\
\mathrm{Pt}-\left(\mathrm{RuO}_{2}-\mathrm{PbO}_{x}\right) / \mathrm{C} \\
\mathrm{Pt}-\left(\mathrm{IrO}_{2}-\mathrm{PbO}_{x}\right) / \mathrm{C} \\
\end{array}$ & $\mathrm{XRD}, \mathrm{EDX}$ & $\begin{array}{l}\mathrm{Pt}(\mathrm{II}), \mathrm{Ru}(\mathrm{III}), \mathrm{Pb}(\mathrm{II}), \mathrm{Ir}(\mathrm{III}) \\
\text { acetylacetonates in a mixture of ethanol } \\
\text { and acetic acid/carbon black powder } \\
\text { (Vulcan XC72R) }\end{array}$ & {$[55]$} \\
\hline Methanol and ethanol & $\begin{array}{c}\mathrm{Pt} \\
\mathrm{Pt}-\mathrm{SnO}_{2} \\
\mathrm{Pt}-\mathrm{Ta}_{2} \mathrm{O}_{5}\end{array}$ & $\begin{array}{l}\text { XRD, EDX, SEM, } \\
\text { AFM }\end{array}$ & $\begin{array}{l}\mathrm{Pt}(\mathrm{II}) \text { acetylacetonate, } \mathrm{Sn}(\mathrm{IV}) \\
\text { bis(acetylacetonate) dibromide, Ta (V) } \\
\text { ethoxide in a mixture of isopropyl alcohol } \\
\text { and acetic acid }\end{array}$ & {$[61]$} \\
\hline - & Pt oxides & TEM, XPS & $\begin{array}{l}\text { Pt (II) acetylacetonate in a mixture of } \\
\text { ethanol and acetic acid }\end{array}$ & {$[64]$} \\
\hline
\end{tabular}

composite electrode ( $\left.\mathrm{Pt}-\mathrm{RuO}_{2}-\mathrm{RhO}_{2} / \mathrm{BDD}\right)$ if compared to the other two materials. Consequently, the current densities on that coating remain higher and diffusion controlled for a considerable amount of time (or charge) thus making the catalyst containing $\mathrm{Pt}, \mathrm{RuO}_{2}$, and $\mathrm{RhO}_{2}$ deposited on BDD by the sol-gel method a promising composite material to be used in fuel cell anodes.

The modification of the BDD electrode with other Ptmetal oxide catalysts prepared by sol-gel has been investigated with the aim to improve its electrocatalytic response to be used as a fuel cell anode. In this context, BDD electrodes with $\mathrm{IrO}_{2}, \mathrm{PbO}_{2}, \mathrm{SnO}_{2}, \mathrm{Ta}_{2} \mathrm{O}_{5}$ and some mixed composites prepared by sol-gel have been investigated by electrochemical techniques to establish their catalytic activity towards methanol and/or ethanol oxidation reactions [49-61]. In Table 2 are presented different coating catalysts synthesized by sol-gel technique on BDD support electrode, indicating the precursors used in the synthesis, and the electro-oxidation reaction that was studied. In all cases a Nafion film was incorporated onto the modified BDD to improve the stability of the coating on the diamond surface. It is worthwhile noticing that all the routes proposed are those using metallic alkoxides dissolved in alcohol prepared by an acid catalyzed hydrolysis.

The surface modification of $\mathrm{BDD}$ with $\mathrm{IrO}_{2}$ and $\mathrm{PbO}_{2}$ was studied by AFM technique and the results indicated the existence of sites with heterogeneous deposition; both catalysts showed good electrocatalytic activity; however, $\mathrm{IrO}_{2} / \mathrm{BDD}$ electrode exhibits better performance for the OER with respect to diamond (unmodified) and $\mathrm{PbO}_{2} / \mathrm{BDD}$ electrodes, as demonstrated by Suffredini et al. [49].

Recently, Salazar-Banda et al. [61] presented similar study, for the preparation of BDD film surfaces modified with $\mathrm{Pt}, \mathrm{Pt}-\mathrm{SnO}_{2}$, and $\mathrm{Pt}-\mathrm{Ta}_{2} \mathrm{O}_{5}$ nanocrystalline deposits by means of sol-gel method, to evaluate the methanol and ethanol oxidation. The characterization of the BDD modified electrodes was accomplished by XRD, AFM, SEM, and EDX studies. The authors estimated (from XRD diffractograms) the mean crystallite size for $\mathrm{Pt}, \mathrm{Pt}-\mathrm{SnO}_{2}$, and $\mathrm{Pt}-\mathrm{Ta}_{2} \mathrm{O}_{5}$ coatings, achieving values of 4.6, 5.0, and $9.1 \mathrm{~nm}$, respectively.

Figure 11 shows the voltammograms obtained on a nonmodified BDD electrode without (solid line curve) and in the presence of $0.5 \mathrm{M}$ of methanol, and ethanol (dashed and dotted lines, resp.). In this figure it is possible to observe that methanol and ethanol are not electroactive in the potential region commonly used to evaluate the fuel cell systems (from 0.4 to $0.8 \mathrm{~V}$ versus HESS). Based on these results, it is possible to observe that this electrode showed onset potential (taken at $i=0.5 \mathrm{~mA} \mathrm{~cm}^{-1}$ ), respectively, to 1.49 and $1.54 \mathrm{~V}$ for the methanol and ethanol oxidation process, in accordance with the insert in Figure 11. The possible explanation for this behavior is maybe due to the low adsorption of species characteristics of diamond surfaces. In light of these results, the substrate, when modified 

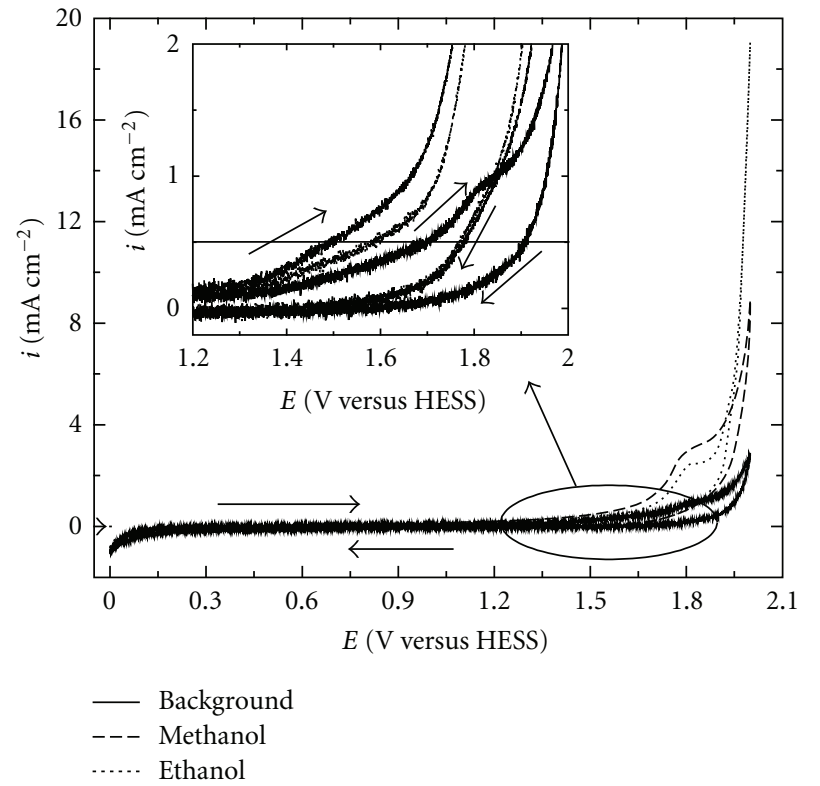

Figure 11: Comparative voltammetric study (first cycle) for the oxidation of methanol (dashed line) and ethanol (dotted line) in $0.5 \mathrm{M} \mathrm{H}_{2} \mathrm{SO}_{4}$ and background responses in the supporting electrolyte (solid line), recorded used a nonmodified BDD electrode, $v=5 \mathrm{mV} \mathrm{s}^{-1}$ (reprinted with permission from [61]).

presents, a small capacitive current, and the study of the alcohols oxidation processes is facilitated, because they do not compete with these reactions.

Potentiostatic polarization experiments (data obtained in the potentiostatic mode after $300 \mathrm{~s}$ polarization at each potential) showed in Figure 12 indicate that the addition of $\mathrm{Ta}_{2} \mathrm{O}_{5}$ to a Pt-containing catalyst decreases the poisoning effect caused by the strongly adsorbed $\mathrm{CO}$ species generated during the oxidation of methanol, changing the reaction onset $170 \mathrm{mV}$ toward less positive potentials, whereas the addition of $\mathrm{SnO}_{2}$ moderately enhances the catalytic activity toward this alcohol oxidation.

On the other hand, the mixture of $\mathrm{SnO}_{2}$ or $\mathrm{Ta}_{2} \mathrm{O}_{5}$ to Pt compounds produces more reactive electrocatalysts for the oxidation of ethanol in acidic media and changes the reactions onsets by 190 or $150 \mathrm{mV}$ toward less positive potentials, respectively. This synergic effect indicates that the addition of these cocatalysts inhibits the poisoning effect caused by the strongly adsorbed intermediary species. Since the Pt-SnO ${ }_{2}$ catalyst was more efficient than $\mathrm{Pt}-\mathrm{Ta}_{2} \mathrm{O}_{5}$ for the oxidation of ethanol, it suggests that probably the tin oxide co-catalyst facilitates the cleavage of the C-C bond of the adsorbed intermediate fragments better than tantalum oxide. However, additional studies to confirm this point must be performed.

Since no loss or diminution of the catalytic activities of the electrodes was observed during the whole experiments, these deposits also showed a high stability on the diamond surfaces as already demonstrated for sol-gel-made composites deposited on BDD surfaces.
These authors concluded that the catalysts containing $\mathrm{Pt}$ and $\mathrm{SnO}_{2}$ deposited on BDD by the sol-gel method are very promising composite materials to be further studied as anodes (high-area BDD substrates) for ethanol oxidation. In addition, catalyst containing $\mathrm{Pt}$ and $\mathrm{Ta}_{2} \mathrm{O}_{5}$ are very interesting composite materials to be used in direct methanol fuel cell anodes. Finally the authors suggested the Pt$\mathrm{SnO}_{2}$ and $\mathrm{Pt}-\mathrm{Ta}_{2} \mathrm{O}_{5}$ deposition on high-area BDD material (powder or felt) to further test as anodes in fuel cells applications.

In this context, in 2007, Salazar-Banda et al. [59], reported an interesting and innovate research where they carried out the modification of BDD powder with metallic oxides $\left(\mathrm{Pt}-\mathrm{RuO}_{x}\right)$ using the sol-gel technique to prepare high-area and stable surface electrodes to methanol oxidation, and its comparison with a commercial catalyst $(\mathrm{Pt}-\mathrm{Ru} / \mathrm{C}) . \mathrm{Pt}-\mathrm{RuO}_{x} / \mathrm{BDD}$ powder electrode was electrochemically evaluated by means of $\mathrm{CV}$, obtaining that the incorporation of ruthenium presents the inhibition of the hydrogen adsorption/desorption signals. Additionally, good performances on currents were observed in the double layer region due to an increase of the capacitive currents and to the ruthenium redox processes, in accordance with the inset of Figure 13. As seen in Figure 13, methanol oxidation, onset potentials $\left(i=0.04 \mathrm{~mA} \mathrm{~cm}^{-2}\right)$, displayed close values on both electrodes $(\sim 0.40 \mathrm{~V}$ versus HESS). Furthermore, the magnitude of the current densities in the common fuel cell operation was approximately from 0.4 to $0.8 \mathrm{~V}$ versus HESS. As a consequence, the BDD powder modification presented an important enhancement of the catalytic activity to methanol oxidation with respect to other materials such as carbon-modified composites.

At the same time, analogous idea was recently proposed by Swope et al. [62], where they have prepared conductive diamond powders as a new catalyst for fuel cells. They have reported the development of higher surface area, approximately $100 \mathrm{~m}^{2} \mathrm{~g}^{-1}$, and good corrosion resistance by conductive diamond powders for application as the electrocatalyst support, using electrodeposition. For this investigation, they carried out the electrochemical measurements using a glassy carbon rotating disk electrode (GC RDE) as the substrate. As illustrated in Figure 14, the larger background current for the $500 \mathrm{~nm}$ diamond powder electrode was due to higher specific area. However, no reduction and oxidation signal was observed between -500 to $700 \mathrm{~V}$, suggesting that the electrode surface is largely free of $\mathrm{sp}^{2}$ carbon impurities. Moreover, they affirmed that the featureless backgrounds for the voltammograms are evidence of good particle conductive.

The same research group [63] subsequently reported the platinization of boron-doped ultrananocrystalline diamond (B-UNCD). Clearly, B-UNCD possesses the requisite electrical conductivity (ca. $0.5 \mathrm{~S} / \mathrm{cm}$ ) and specific surface area (ca. $170 \mathrm{~m}^{2} / \mathrm{g}$ ) for a viable electrocatalyst support and, more importantly, the material exhibited excellent carbon corrosion resistance in the presence of Pt. XRD and TEM were used to characterized the Pt particle size and distribution on the diamond powder. A chemical impregnationreduction method was used for Pt deposition. Pt particles 


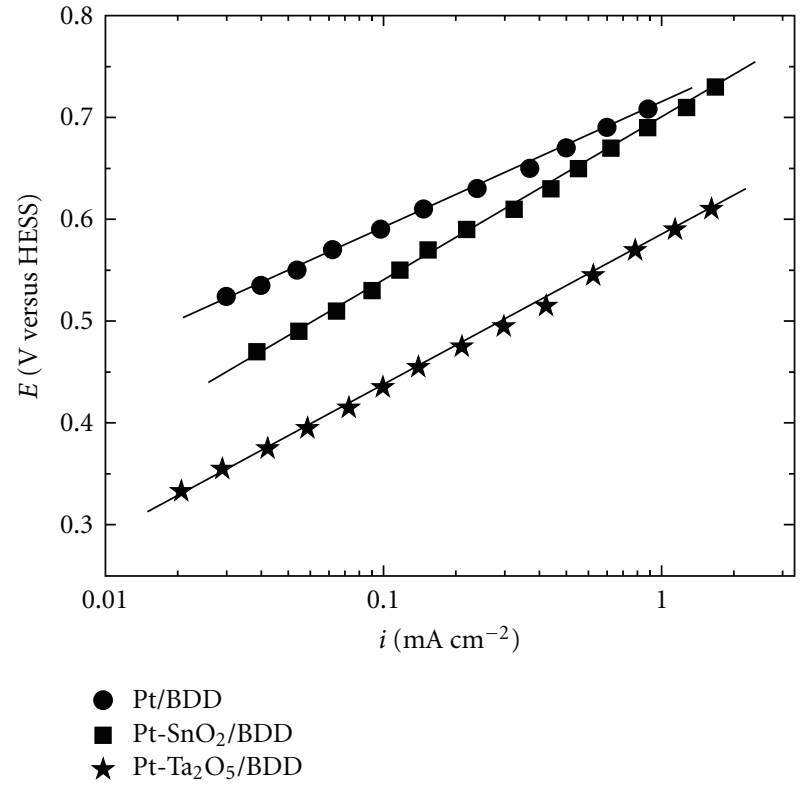

(a)

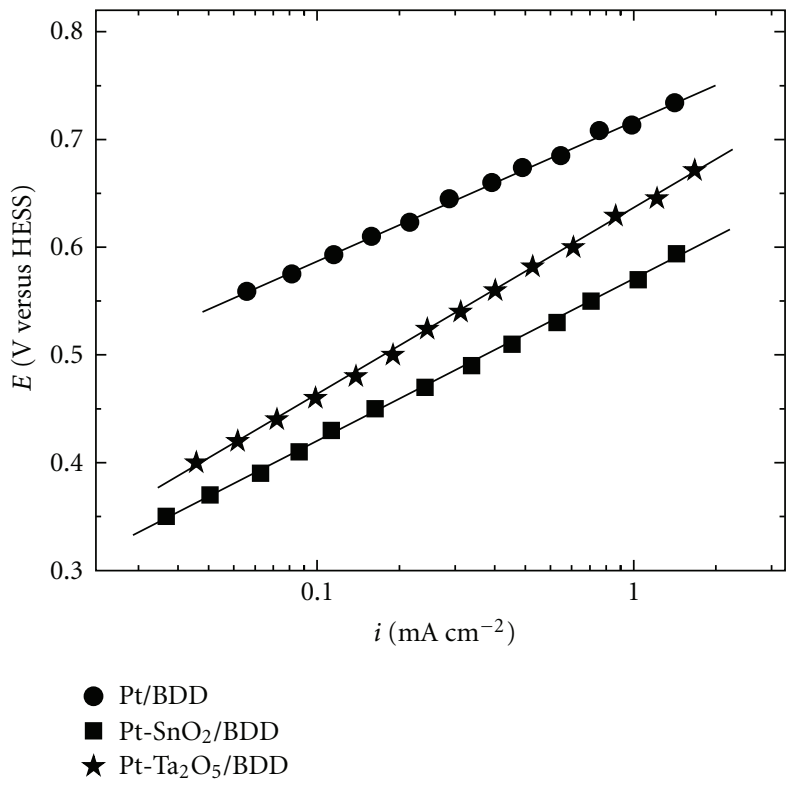

(b)

FIGURE 12: Steady-state polarization curves plotted as the corresponding Tafel plots for the electrochemical oxidation of methanol $0.5 \mathrm{M}$ (a) and ethanol 0.5 M (b) dissolved in $0.5 \mathrm{M} \mathrm{H}_{2} \mathrm{SO}_{4}$ and recorded for the Pt/BDD (spheres), $\mathrm{Pt}-\mathrm{SnO}_{2} / \mathrm{BDD}$ (squares), and Pt-Ta $\mathrm{O}_{5} / \mathrm{BDD}$ (stars) electrode surfaces (reprinted with permission from [61]).

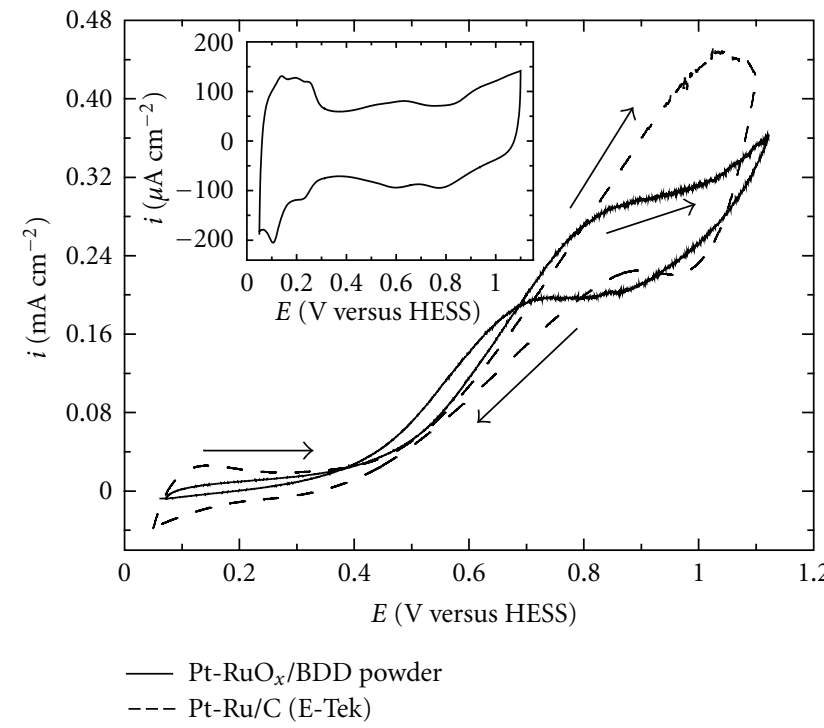

Figure 13: Cyclic voltammograms for the electrochemical oxidation of $0.5 \mathrm{M}$ of methanol in $0.5 \mathrm{M} \mathrm{H}_{2} \mathrm{SO}_{4}$ aqueous solution carry out on the $\mathrm{Pt}-\mathrm{RuO}_{x} / \mathrm{BDD}$ powder/BDD (solid line) and on the $\mathrm{Pt}-\mathrm{Ru} / \mathrm{C} / \mathrm{BDD}$ (dashed line) electrodes at $v=10 \mathrm{mV} \mathrm{s}^{-1}$. Insert correspond to the Cyclic voltammogram recorded on the $\mathrm{Pt}-\mathrm{RuO}_{x} / \mathrm{BDD}$ powder/BDD electrode in $0.5 \mathrm{M} \mathrm{H}_{2} \mathrm{SO}_{4}$ aqueous solution at $\nu=50 \mathrm{mV} \mathrm{s}^{-1}$ (reprinted with permission from [59]).

were uniformly distributed on B-UNCD using this method. The nominal particle size was approximately $5 \mathrm{~nm}$. A highresolution TEM image of a $\mathrm{Pt}$ nanoparticle formed on diamond particle is shown in Figure 15. The Pt metal

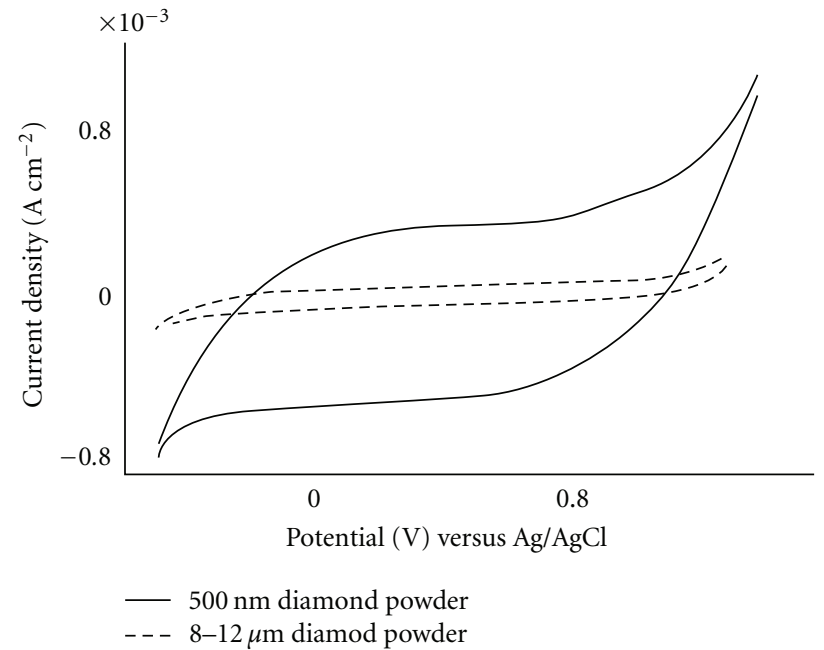

FIGURE 14: Cyclic Voltammogram for an 8-12 $\mu \mathrm{m}$ diamond powder electrode, grown under microcrystalline conditions, and a 500 $\mathrm{nm}$ diamond powder electrode, grown under nanocrystalline conditions. Experiments were carried out in $1 \mathrm{M} \mathrm{KCl}$ at $100 \mathrm{mV} \mathrm{s}^{-1}$ (reprinted with permission from [62]).

particles bonded directly to the diamond surface with no graphitic interfacial layer. The small lattice misfit of $10 \%$ between the Pt (111) and diamond (111) crystallographic orientations is good for bond formation between the two phases with low internal stress. Good electronic coupling between $\mathrm{Pt}$ and diamond was indicated by the Pt $4 \mathrm{f}$ binding energy shift of $0.6 \mathrm{eV}$ from $70.8 \mathrm{eV}$ for the bulk metal 


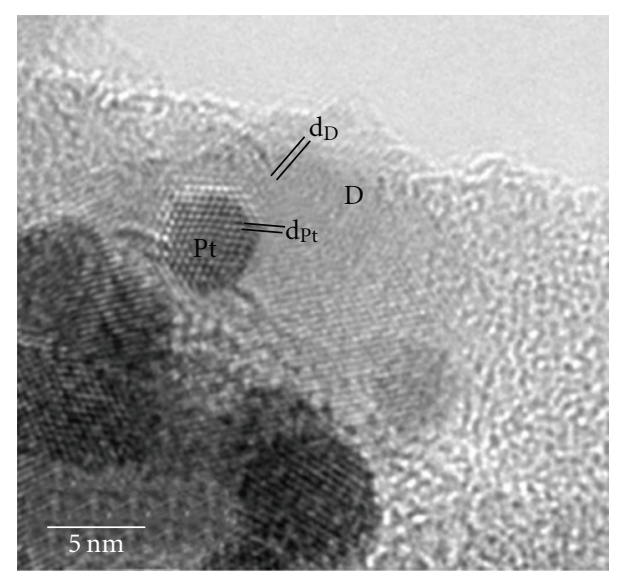

FIGURE 15: High-resolution TEM image of a Pt particle formed on B-UNCD-D. The Pt loading was $5 \% \mathrm{Pt} / \mathrm{C}$ and the metal at layer was formed by a chemical impregnation method. $\mathrm{P}$ is the platinum particle, $\mathrm{D}$ is the diamond, and $\mathrm{d}_{\mathrm{Pt}}$ and $\mathrm{d}_{\mathrm{D}}$ are the lattice spacing for Pt and diamond (Reprinted with permission from [63]).

to $71.4 \mathrm{eV}$ for $\mathrm{Pt}$ on diamond; a binding energy that was close to that for Pt supported on $\mathrm{sp}^{2}$-bonded carbon supports. The gas-phase oxidation of the bare and platinized powders in air was studied by TGA (Thermogravimetric Analysis). Commercial Vulcan XC-72 and platinized Vulcan XC-72 at a $20 \% \mathrm{wt} \%$ were used for comparison. A more rapid and reliable assessment of the dimensional stability of carbon electrocatalyst supports is possible using this method, in comparison with traditional long-term fuel cell testing. There are parallels between the relative thermal stability in an oxygen-containing atmosphere and the relative support stability in an operating fuel cell. The results clearly demonstrate that platinized diamond is more resistant to gas phase oxidation than is platinized Vulcan at elevated temperatures. Those results could indicate that the platinized diamond material possesses greater resistance to electrochemical corrosion.

Boron-doped diamond nanoparticles were recently prepared in nanosize undoped diamond particles showing a great improvement in conductivity and surface capacitance with a negligible activity in its potential window [64]. The sol-gel method deposited Pt oxide nanoparticles on the undoped diamond nanoparticles as well as on the BDD nanoparticles. The CV of the depositions was consistent with the higher conductivity and lower surface capacitance of the BDD nanoparticles shown by the comparison between the doped and undoped diamond nanoparticles. Also, BDD nanoparticles favored the formation of different planes of Pt in the deposition. Since, the first peak (lowest potential) in Figure 16 was at the same potential for each material, and the other peaks differ from each different configuration, showing different Pt planes. The authors concluded that the accomplishment of this letter paper opens unlimited opportunities, the use as a support for catalysts for alkaline fuel cells as well as for waste water management, among others.

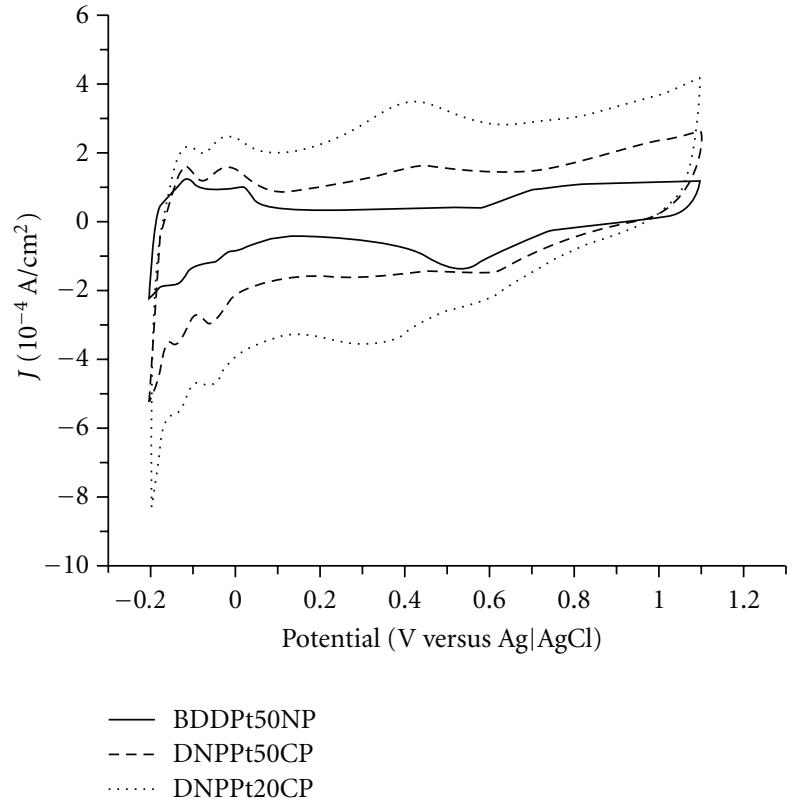

FIGURE 16: Cyclic voltammetry of BDD nanoparticles with $50 \mathrm{wt} \%$ $\mathrm{Pt}$ (BDDPt50NP), undoped diamond nanoparticles with $50 \mathrm{wt} \% \mathrm{Pt}$ (DNPPt50CP), and with $20 \mathrm{wt} \% \mathrm{Pt}$ (DNPPt20CP) in $0.5 \mathrm{M} \mathrm{H}_{2} \mathrm{SO}_{4}$ (reprinted with permission from [64]).

\section{Application of BDD Films in Batteries}

Both primary and rechargeable batteries, which can generate clean electric energy from the stored chemical energy through the desired electrochemical reactions, are essential to the convenience and sustainability of human development in the modern mobile society [65]. Rechargeable batteries are currently prevailing portable power sources because they are material saving due to repeated charge and discharge. Nowadays, environmental awareness and high energy density demand lead to the popularity of Li ion and Ni-MH batteries, which have gradually become an alternative power source to traditional lead acid and Ni-Cd batteries [65]. Rechargeable Li ion battery systems have become a prominent technology in the global battery market, since they offer the highest energy density available to date for rechargeable batteries.

Current research and development of $\mathrm{Li}$ ion batteries can hardly keep up with the growing demand of the everincreasing 3C (computer, communication, and consumer electronics) market. New-generation wireless communication technologies require batteries with lighter weight, higher energy/power density, and longer cycle life. Commercial $\mathrm{Li}$ ion batteries generally utilize classic $\mathrm{Li}^{+}$intercalation compounds $\left(\mathrm{LiCoO}_{2}\right)$ and carbons as active materials, which fall in short with limited inherent capacity [66].

Although the lithium anode has superior theoretical capacity $\left(3.862 \mathrm{mAh} \mathrm{g}^{-1}\right)$ and a high redox potential, there are several problems like dendrite and poor cyclability to be resolved before it can have practical applications [6769]. In the last two decades, numerous researchers have endeavored to find solutions to this problem by introducing 


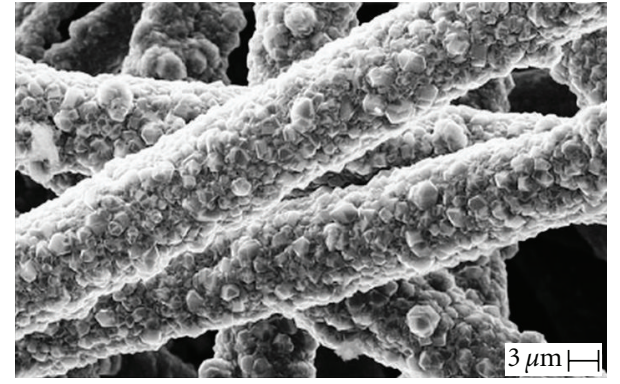

FIGURE 17: SEM image of BDD/CF electrode with a doping level of $10^{18}$ part $\mathrm{cm}^{-3}$ (reprinted with permission from [78]).

different solvent mixtures [70], novel electrolyte salts [71], and additives to the electrolytes $[72,73]$.

Carbonaceous anodes are the most used anodic materials due to their low cost and availability. However, the theoretical capacity $\left(372 \mathrm{mAh} \mathrm{g}^{-1}\right)$ is poor compared with the charge density of lithium $\left(3.862 \mathrm{mAh} \mathrm{g}^{-1}\right)$. Some efforts with novel graphite varieties and carbon nanotubes have tried to increase this reversible capacity. Reported measurements to date of the lithium ion capacity for single walled carbon nanotubes (SWCNTs) are generally between 400 and $460 \mathrm{mAhg}^{-1}[74,75]$. However, there is a large first cycle hysteresis that leads to high irreversible capacity loss for SWCNTs. This effect has been attributed to the high surface area of SWCNTs, which affects the extent of solvent decomposition leading to the solid-electrolyteinterface formation [74].

As a substitute material, BDD electrodes have very interesting properties (see Section 1). BDD films were early used as substrates for the deposition of $\mathrm{Al}$ thin films for the study of the underpotential deposition (UPD) of lithium as an indirect application of diamond for battery systems [76]. Thus, the electrochemical properties of clean aluminum in $\mathrm{LiClO}_{4}$ (poly(ethylene oxide)) solutions have been investigated in ultrahigh vacuum using as electrodes both foils and thin films vapor deposited on BDD layers supported on $\mathrm{Si}$ substrates. Voltammetric scans recorded at temperatures of about $55^{\circ} \mathrm{C}$ yielded a set of deposition/stripping peaks at potentials more positive to the onset of $\mathrm{Li} / \mathrm{Al}$ alloy formation, attributed to Li UPD on Al. The amount of stored Li was found to increase with the thickness of the Al film; however, uncertainties in the real amount of $\mathrm{Al}$ did not allow more quantitative conclusions to be drawn.

The use of diamond materials in studies for further battery applications is rather recent. The direct insertion of lithium into as prepared $\mathrm{H}$-terminated BDD electrodes with different levels of boron doping $\left(10^{18}-10^{21} \mathrm{~B} \mathrm{~cm}^{-3}\right)$ and grown on cloth of graphite fibers was demonstrated in 2003 by Ferreira and coworkers [77].

The effect of boron concentration was evident. Electrodes with lower boron content displayed higher capacity for reversible lithium insertion, although they present a smaller electronic conductivity that increases the ohmic drop of the electrode. The electrode with $10^{21}$ part $\mathrm{cm}^{-3}$ reached a

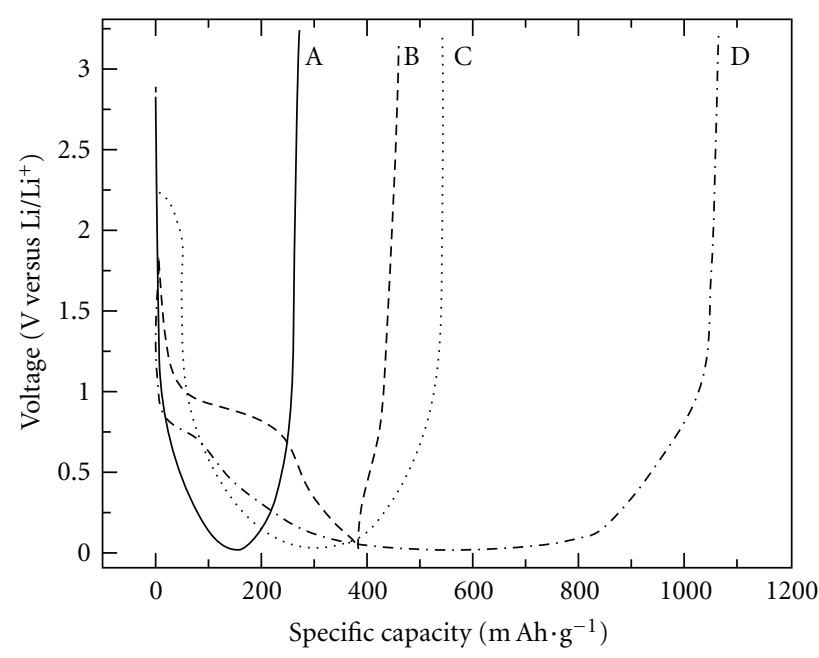

FIGURE 18: First charge/discharge for carbon felt (A) and BDD/CF electrodes doped from $10^{18}$ up to $10^{21}$ part $\mathrm{cm}^{-3}$ (B, C, D) (reprinted with permission from [77]).

specific capacity, during the first insertions, of $95.7 \mathrm{mAh} \mathrm{g}^{-1}$, while the sample with $10^{18}$ part $\mathrm{cm}^{3}$ reached $234.9 \mathrm{mAh} \mathrm{g}^{-1}$.

A continuation of this research was reported in 2005 when the authors investigated the lithium electrochemical intercalation into BDD films grown on carbon felt (BDD/CF electrodes, see Figure 17) also with different boron doping levels $\left(10^{18}-10^{21} \mathrm{~B} \mathrm{~cm}^{-3}\right)$ [78]. The grain sizes and conductivity of the BDD layers had great influence in the lithium intercalation process.

In contrast to the first study (BDD grown on graphite fibers) [77], higher electronic conductivity (higher boron doping level) increased the reversible electrode capacity of the BDD grown on carbon felt. Composite electrodes containing diamond layers with higher boron concentration $\left(10^{21}\right.$ part $\mathrm{cm}^{-3}$, curve D in Figure 18) have also smaller grain sizes, and as a consequence are rich in grain boundaries or $\mathrm{sp}^{2}$ sites, displayed the highest reversible capacity for lithium storage. On the contrary, the low doped diamond layer with a boron concentration of $10^{18}$ part $\mathrm{cm}^{-3}$ (curve $B$ in Figure 18), that has large grain sizes and low electronic conductivity, was not efficient for lithium storage and intercalation. Nevertheless, the reason for these incongruous results from the two studies was unclear and was not fully explored in the study.

According to these authors, this new class of electrodes can be very useful since they are free of the binder polymers traditionally used in the preparation of lithium batteries. Hypothetically, BDD composite electrodes can become very competitive if a boron-diamond layer providing an elevated $\mathrm{sp}^{2} / \mathrm{sp}^{3}$ sites ratio. In this sense, nanodiamond layers, with a large quantity of grain boundaries, grown on felt substrates deserve further investigation.

The study of the cycling performance of BDD powder prepared by the chemical vapor deposition method by assembling Li/BDD cells at ambient temperature was recently reported [79]. BDD powders with a doping level of $3500 \mathrm{ppm}$ 
of B were prepared on single crystal p-type Si (100) wafers. The as-grown BDD contained some graphitic $\left(\mathrm{sp}^{2}\right)$ phase and was hydrogen-terminated. Activation of BDD by anodic polarization (in $\mathrm{H}_{2} \mathrm{SO}_{4} 1 \mathrm{M}$ at $25^{\circ} \mathrm{C}$ for $30 \mathrm{~min}$ ) was carried out to eliminate most of the $\mathrm{sp}^{2}$-type carbon and absorbed hydrogen from the surface.

According to Christy and coworkers [79] the diamond grains of the BDD layer have effective participation in the lithium storage, and electron reaches the diamond through the $\mathrm{sp}^{2}$ carbons located in the grain boundaries. Both graphitic and nongraphitic carbons should provide sites for lithium insertion. Graphitic $\mathrm{sp}^{2}$-type carbons accommodate $\mathrm{Li}$ between grapheme layers while the $\mathrm{sp}^{3}$-type carbons can accommodate only in defect sites caused by the presence of the trivalent boron, although it was reported that the lithium insertion in the interstitial sites of the $\mathrm{sp}^{3}$-bonded carbon structure is energetically favorable and that the mobility of $\mathrm{Li}$ in the diamond lattice seems to be elevated [80].

It is worthwhile mentioning that the defect structure and, therefore, the $\mathrm{sp}^{2}$ character can be enhanced by incorporation of more boron in the carbons. Thus the results of Christy and coworkers suggested that BDD anode materials could be very promising if BDD provides an elevated number of both $\mathrm{sp}^{2}$ carbon sites and also $\mathrm{sp}^{3}$ sites with good intercalation kinetics. This supposition is reinforced if it is considered that a high fraction of $\mathrm{sp}^{2}$ carbon is preferred for high lithium storage capacity when as-deposited diamondlike carbon (DLC) films with different $\mathrm{sp}^{2} / \mathrm{sp}^{3}$ ratios were characterized as anode materials for Li-ion batteries [81]. DLC is a metastable form of amorphous carbon containing $\mathrm{sp}^{2}$-bonded clusters interconnected by a random network of $\mathrm{sp}^{3}$-bonded atomic sites [82].

In a different approach, functional $\mathrm{sp}^{2}-\mathrm{sp}^{3}$ carbon composite materials (carbon nanotube/nanohoneycomb BDD, CNT-NANO) were fabricated by introducing multiwalled carbon nanotubes (MWCNs) into the pores of nanohoneycomb diamond of $400 \mathrm{~nm}$ diam. using the CVD method [83].

Highly BDD films were deposited by microwave-assisted plasma CVD. Nanohoneycomb structures were prepared by oxygen plasma etching through anodic alumina masks with $400 \mathrm{~nm}$ pore diameter on polished diamond films, as observed in Figure 19, while, the MWCNs were prepared by pyrolysis of phthalocyanine with an Fe catalyst using CVD.

The electrochemical behavior of these electrodes was examined using $\mathrm{CV}$, electrochemical impedance spectroscopy, and galvanostatic measurements in $\mathrm{LiClO}_{4} /$ propylene carbonate electrolyte. In contrast to the studies above discussed [77-79], neither $\mathrm{Li}^{+}$intercalation nor deintercalation was observed on the cyclic voltammograms for the asdeposited BDD. On the other hand, the behavior of $\mathrm{Li}^{+}$ insertion into CNTs was observed in the cathodic sweep at $-3.3 \mathrm{~V}$ (versus $\mathrm{Ag} / \mathrm{Ag}^{+}$) in $\mathrm{CV}$. The current density for $\mathrm{Li}^{+}$ intercalation at $\mathrm{HD}$ CNT-NANO was $-343 \mu \mathrm{A} \mathrm{cm}^{-2}$ (geometric area), and this at LD CNT-NANO was $-173 \mu \mathrm{A} \mathrm{cm}^{-2}$ (geometric) at $-3.3 \mathrm{~V}$ (versus $\mathrm{Ag} / \mathrm{Ag}^{+}$).

Alternating current (AC) impedance measurements have indicated that at the nanohoneycomb diamond densely deposited CNTs (HD CNT-NANO), only the $\mathrm{Li}^{+}$ intercalation process is observed. In contrast, the nanohoneycomb diamond modified with CNTs in low density (LD CNT-NANO) exhibited the combination behavior of $\mathrm{Li}^{+}$ intercalation at CNTs and the electrochemical double-layer discharging on the diamond surface.

In galvanostatic measurements, HD CNT-NANO behaved as a pure $\mathrm{Li}^{+}$ion battery anode, and the specific capacity (per $1 \mathrm{~g}$ of activated material) was found to be

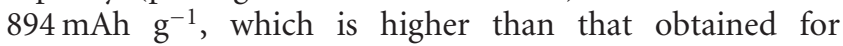
mesophase carbon materials. For LD CNT-NANO, in the initial time following the start of discharging, the behavior of the double-layer discharging was observed in addition to $\mathrm{Li}^{+}$deintercalation. Suppression of the potential drops associated with $\mathrm{Li}^{+}$deintercalation by rapid discharging from the electrical double layer could increase the specific power for LD CNT-NANO. The combination function of the super capacitor and the $\mathrm{Li}^{+}$-ion battery that works simultaneously supporting each other in one electrochemical cell suggests the possible realization of a hybrid electrode material with high energy density and high-specific power.

In summary, two different functionalities were simultaneously realized by combining two different materials with totally different electrochemical characteristics. In this case, the increase in the performance of the one functionality results in the tradeoff of the other functionality. Therefore, in the case of the actual use of this hybrid electrode, the ratio of the combination of $\mathrm{sp}^{2}$ and $\mathrm{sp}^{3}$ carbon must be selected according to the requirement from the application.

\section{Concluding Remarks}

The deposition of metal or metal oxide clusters onto the BDD film electrodes has been used to exploit the much higher catalytic activity of such nanoparticles using only very small catalyst amounts compared to the conventional bulk material. The modification of BDD surfaces with microand nanometric metallic and/or metallic oxide deposits using different methods has been broadly investigated in the last two decades [15-61]. The use of these hybrid systems containing BDD as new anode supports for future fuel cell applications has been widely evaluated and investigated. However, it is difficult to choose the most suitable method for the modification of BDD surfaces at this time, since each method has its own advantages and limitations. The available literature covered in this review clearly indicates that while the microemulsion method produces a welldefined nanoparticles size $(2-5 \mathrm{~nm})$ and good dispersion, the alloy degree is poor. The electrodeposition method produces well-dispersed particles at the BDD surface, but with higher sizes (40-700 nm) and low stability. The sol-gel method produce the highest stable nanoparticles with low particle sizes $(<10 \mathrm{~nm})$ and good dispersion on the BDD surface; however, the control of the alloy degree between the Pt and the ad-atom used is difficult to achieve by this method. The thermal deposition appears as the less suitable method for this purpose due to the low degree of dispersion, high particle size, low stability, and the difficulty to control the degree of alloying when this method is used. 

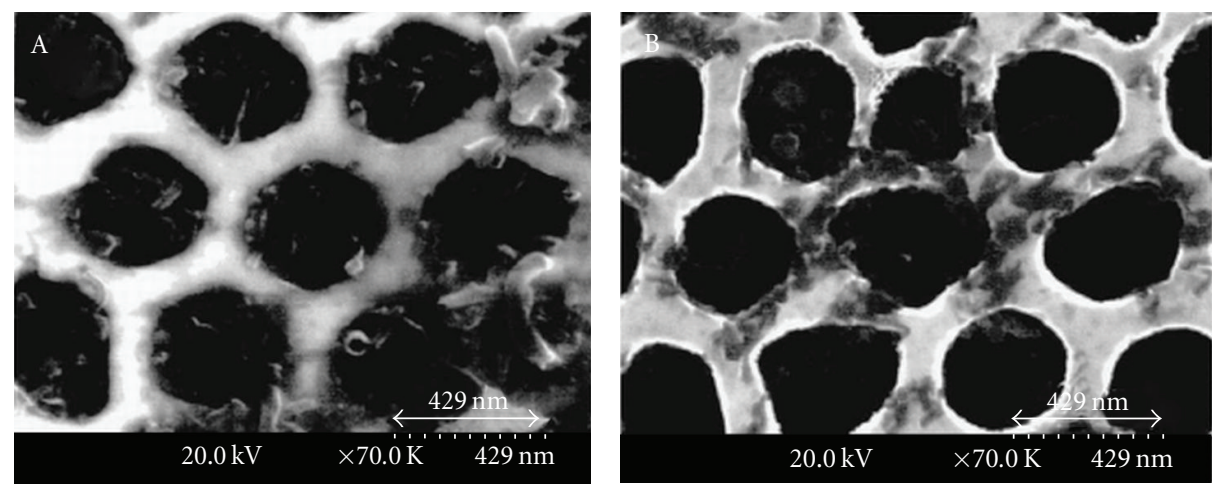

(a)
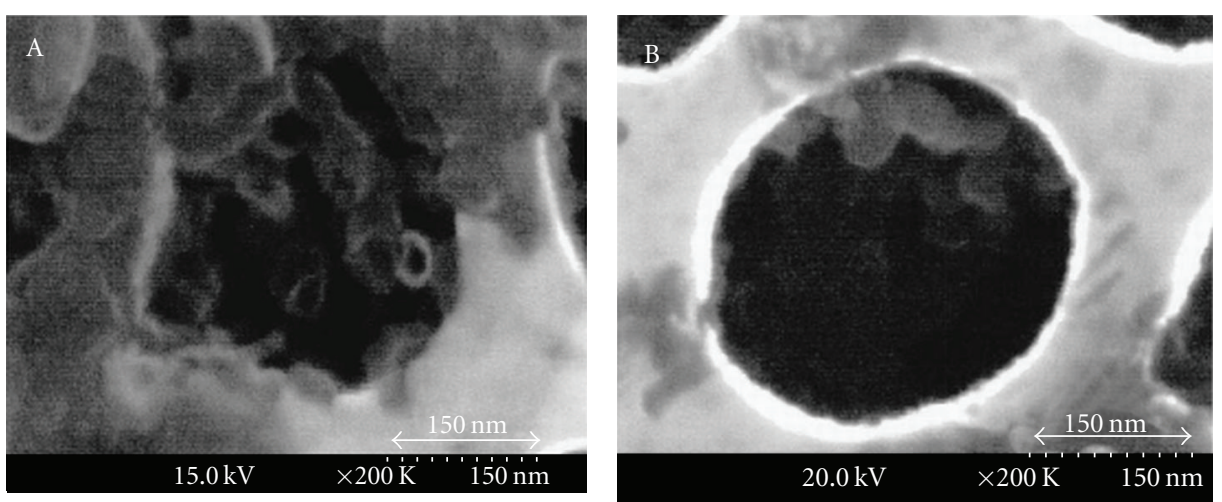

(b)

FIgURE 19: Top view of SEM images for a carbon nanotubes/nanoporous diamond composite electrode; (a) low magnification, and (b) high magnification images for (A) HD CNT-NANO and (B) LD CNT-NANO (reprinted with permission from [83]).

Therefore, further developments should be carried out upon the close collaboration of analytical chemists, engineers, and electrochemists to ensure effective application and exploitation of new catalysts to increase the efficiency of fuel cells using BDD anodes tested in real fuel cell operating conditions.

On the other hand, some efforts should be carried out for the application of BDD materials on rechargeable battery or electrochemical capacitors systems, However, considering the scarce quantity of reports available in the literature and due to the controversial results discussed in this section for the intercalation of lithium ion on BDD materials, it is clear that this issue is in the beginning of development. Several studies must be carried out for the application of BDD materials on rechargeable battery systems. Studies with emphasis on the quantification and understanding of the relationship within the properties of the diamond materials, like $\mathrm{sp}^{2}$-type carbon content, grain boundary size (micro, and nanodiamond), level of doping, diamond conductivity, surface termination, among others, on the lithium intercalation behavior are still needed. Future outlooks are apparently related to the use of boron-doped nanodiamond materials with high levels of doping, joining both, a high $\mathrm{sp}^{2} / \mathrm{sp}^{3}$ carbon ratio and a high quantity of atomic defect sites. This direction would be a worthwhile area to pursue for research and technological applications for anode materials for battery systems.

\section{Acknowledgment}

The authors wish to thank National Council of Technological and Scientific Development-CNPq (Proc. 304018/2009-0) for the scholarships and financial support to this work.

\section{References}

[1] H. A. Gasteiger, S. S. Kocha, B. Sompalli, and F. T. Wagner, "Activity benchmarks and requirements for Pt, Pt-alloy, and non-Pt oxygen reduction catalysts for PEMFCs," Applied Catalysis B, vol. 56, no. 1-2, pp. 9-35, 2005.

[2] M. S. Saha, R. Li, and X. Sun, "High loading and monodispersed Pt nanoparticles on multiwalled carbon nanotubes for high performance proton exchange membrane fuel cells," Journal of Power Sources, vol. 177, no. 2, pp. 314-322, 2008.

[3] S. Mitsushima, S. Kawahara, K. I. Ota, and N. Kamiya, "Consumption rate of Pt under potential cycling," Journal of the Electrochemical Society, vol. 154, no. 2, pp. B153-B158, 2007.

[4] D. A. Stevens, M. T. Hicks, G. M. Haugen, and J. R. Dahn, "Ex situ and in situ stability studies of PEMFC catalysts," Journal of the Electrochemical Society, vol. 152, no. 12, pp. A2309-A2315, 2005.

[5] S. Brimaud, C. Coutanceau, E. Garnier et al., "Influence of surfactant removal by chemical or thermal methods on structure and electroactivity of $\mathrm{Pt} / \mathrm{C}$ catalysts prepared by water-in-oil microemulsion," Journal of Electroanalytical Chemistry, vol. 602, no. 2, pp. 226-236, 2007. 
[6] U. Griesbach, D. Zollinger, H. Pütter, and C. Comninellis, "Evaluation of boron doped diamond electrodes for organic electrosynthesis on a preparative scale," Journal of Applied Electrochemistry, vol. 35, no. 12, pp. 1265-1270, 2005.

[7] P. Cañizares, A. Gadri, J. Lobato et al., "Electrochemical oxidation of azoic dyes with conductive-diamond anodes," Industrial and Engineering Chemistry Research, vol. 45, no. 10, pp. 3468-3473, 2006.

[8] R. T. S. Oliveira, G. R. Salazar-Banda, M. C. Santos et al., "Electrochemical oxidation of benzene on boron-doped diamond electrodes," Chemosphere, vol. 66, no. 11, pp. 2152 2158, 2007.

[9] M. A. Rodrigo, P. A. Michaud, I. Duo, M. Panizza, G. Cerisola, and C. Comninellis, "Oxidation of 4-chlorophenol at borondoped diamond electrode for wastewater treatment," Journal of the Electrochemical Society, vol. 148, no. 5, pp. D60-64, 2001.

[10] B. Boye, P. A. Michaud, B. Marselli, M. M. Dieng, E. Brillas, and C. Comninellis, "Anodic oxidation of 4chlorophenoxyacetic acid on synthetic boron-doped diamond electrodes," New Diamond and Frontier Carbon Technology, vol. 12, no. 2, pp. 63-72, 2002.

[11] I. Sirés, N. Oturan, M. A. Oturan, R. M. Rodríguez, J. A. Garrido, and E. Brillas, "Electro-fenton degradation of antimicrobials triclosan and triclocarban," Electrochimica Acta, vol. 52, no. 17, pp. 5493-5503, 2007.

[12] C. Flox, J. A. Garrido, R. M. Rodríguez et al., "Mineralization of herbicide mecoprop by photoelectro-fenton with UVA and solar light," Catalysis Today, vol. 129, no. 1-2, pp. 29-36, 2007.

[13] G. S. Garbellini, G. R. Salazar-Banda, and L. A. Avaca, "Effects of ultrasound on the degradation of pentachlorophenol by boron-doped diamond electrodes," Portugaliae Electrochimica Acta, vol. 28, no. 6, pp. 405-415, 2010.

[14] J. H. T. Luong, K. B. Male, and J. D. Glennon, "Boron-doped diamond electrode: synthesis, characterization, functionalization and analytical applications," Analyst, vol. 134, no. 10, pp. 1965-1979, 2009.

[15] Y. Shao, J. Liu, Y. Wang, and Y. Lin, "Novel catalyst support materials for PEM fuel cells: current status and future prospects," Journal of Materials Chemistry, vol. 19, no. 1, pp. 46-59, 2009.

[16] A. Kraft, "Doped diamond: a compact review on a new, versatile electrode material," International Journal of Electrochemical Science, vol. 2, pp. 355-385, 2007.

[17] M. Boutonnet, S. Lögdberg, and E. E. Svensson, "Recent developments in the application of nanoparticles prepared from w/o microemulsions in heterogeneous catalysis," Current Opinion in Colloid and Interface Science, vol. 13, no. 4, pp. 270 286, 2008.

[18] S. Eriksson, U. Nylén, S. Rojas, and M. Boutonnet, "Preparation of catalysts from microemulsions and their applications in heterogeneous catalysis," Applied Catalysis A, vol. 265, no. 2, pp. 207-219, 2004.

[19] M. Boutonnet, J. Kizling, P. Stenius, and G. Maire, "The preparation of monodisperse colloidal metal particles from microemulsions," Colloids and Surfaces, vol. 5, no. 3, pp. 209225, 1982.

[20] G. Siné and C. Comninellis, "Nafion ${ }^{\circledR}$-assisted deposition of microemulsion-synthesized platinum nanoparticles on BDD: activation by electrogenerated $\cdot \mathrm{OH}$ radicals," Electrochimica Acta, vol. 50, no. 11, pp. 2249-2254, 2005.

[21] G. Siné, I. Duo, B. El Roustom, G. Fóti, and C. Comninellis, "Deposition of clusters and nanoparticles onto boron-doped diamond electrodes for electrocatalysis," Journal of Applied Electrochemistry, vol. 36, no. 8, pp. 847-862, 2006.

[22] G. Siné, G. Fóti, and C. Comninellis, "Boron-doped diamond (BDD)-supported $\mathrm{Pt} / \mathrm{Sn}$ nanoparticles synthesized in microemulsion systems as electrocatalysts of ethanol oxidation," Journal of Electroanalytical Chemistry, vol. 595, no. 2, pp. 115-124, 2006.

[23] G. Siné, D. Smida, M. Limat, G. Fóti, and C. Comninellis, "Microemulsion synthesized $\mathrm{Pt} / \mathrm{Ru} / \mathrm{Sn}$ nanoparticles on BDD for alcohol electro-oxidation," Journal of the Electrochemical Society, vol. 154, no. 2, pp. B170-B174, 2007.

[24] F. Cardarelli, P. Taxil, A. Savall, C. Comninellis, G. Manoli, and O. Leclerc, "Preparation of oxygen evolving electrodes with long service life under extreme conditions," Journal of Applied Electrochemistry, vol. 28, no. 3, pp. 245-250, 1998.

[25] I. Duo, P. A. Michaud, W. Haenni, A. Perret, and C. Comninellis, "Activation of boron-doped diamond with $\mathrm{IrO}_{2}$ clusters," Electrochemical and Solid-State Letters, vol. 3, no. 7, pp. 325-326, 2000.

[26] B. E. Roustom, G. Fóti, and C. Comninellis, "Preparation of gold nanoparticles by heat treatment of sputter deposited gold on boron-doped diamond film electrode," Electrochemistry Communications, vol. 7, no. 4, pp. 398-405, 2005.

[27] F. Montilla, E. Morallón, I. Duo, C. Comninellis, and J. L. Vázquez, "Platinum particles deposited on synthetic borondoped diamond surfaces. Application to methanol oxidation," Electrochimica Acta, vol. 48, no. 25-26, pp. 3891-3897, 2003.

[28] A. De Battisti, S. Ferro, and M. Dal Colle, "Electrocatalysis at conductive diamond modified by noble-metal oxides," Journal of Physical Chemistry B, vol. 105, no. 9, pp. 1679-1682, 2001.

[29] J. S. Gao, T. Arunagiri, J. J. Chen et al., "Preparation and characterization of metal nanoparticles on a diamond surface," Chemistry of Materials, vol. 12, no. 11, pp. 3495-3500, 2000.

[30] M. Li, G. Zhao, R. Geng, and H. Hu, "Facile electrocatalytic redox of hemoglobin by flower-like gold nanoparticles on boron-doped diamond surface," Bioelectrochemistry, vol. 74, no. 1, pp. 217-221, 2008.

[31] V. Saez, J. Gonzalez-Garcia, M. A. Kulandainathan, and F. Marken, "Electro-deposition and stripping of catalytically active iron metal nanoparticles at boron-doped diamond electrodes," Electrochemistry Communications, vol. 9, no. 5, pp. 1127-1133, 2007.

[32] K. E. Toghill, G. G. Wildgoose, A. Moshar, C. Mulcahy, and R. G. Compton, "The fabrication and characterization of a bismuth nanoparticle modified boron doped diamond electrode and its application to the simultaneous determination of cadmium(II)and lead(II)," Electroanalysis, vol. 20, no. 16, pp. 1731-1737, 2008.

[33] G. M. Swain and R. Ramesham, "The electrochemical activity of boron-doped polycrystalline diamond thin film electrodes," Analytical Chemistry, vol. 65, no. 4, pp. 345-351, 1993.

[34] K. B. Holt, A. J. Bard, Y. Show, and G. M. Swain, "Scanning electrochemical microscopy and conductive probe atomic force microscopy studies of hydrogen-terminated borondoped diamond electrodes with different doping levels," Journal of Physical Chemistry B, vol. 108, no. 39, pp. 1511715123, 2004.

[35] C. H. Goeting, F. Jones, J. S. Foord et al., "Electrochemistry at boron-doped diamond films grown on graphite substrates: redox-, adsorption and deposition processes," Journal of Electroanalytical Chemistry, vol. 442, no. 1-2, pp. 207-211, 1998. 
[36] M. Mermoux, B. Marcus, G. M. Swain, and J. E. Butler, "A confocal raman imaging study of an optically transparent borondoped diamond electrode," Journal of Physical Chemistry B, vol. 106, no. 42, pp. 10816-10821, 2002.

[37] D. Becker and K. Jüttner, "Influence of surface inhomogeneities of boron doped CVD-diamond electrodes on reversible charge transfer reactions," Journal of Applied Electrochemistry, vol. 33, no. 10, pp. 959-968, 2003.

[38] D. Becker and K. Jüttner, "The impedance of fast charge transfer reactions on boron doped diamond electrodes," Electrochimica Acta, vol. 49, no. 1, pp. 29-38, 2003.

[39] N. R. Stradiotto, K. E. Toghill, L. Xiao, A. Moshar, and R. G. Compton, "The fabrication and characterization of a nickel nanoparticle modified boron doped diamond electrode for electrocatalysis of primary alcohol oxidation," Electroanalysis, vol. 21, no. 24, pp. 2627-2637, 2009.

[40] J. Wang and G. M. Swain, "Fabrication and evaluation of platinum/diamond composite electrodes for electrocatalysis," Journal of the Electrochemical Society, vol. 150, no. 1, pp. E24E32, 2003.

[41] O. Enea, B. Riedo, and G. Dietler, "AFM study of Pt clusters electrochemically deposited onto boron-doped diamond films," Nano Letters, vol. 2, no. 3, pp. 241-244, 2002.

[42] H. A. Gasteiger, N. Marković, P. N. Ross, and E. J. Cairns, "Methanol electrooxidation on well-characterized PtRu alloys," Journal of Physical Chemistry, vol. 97, no. 46, pp. 12020-12029, 1993.

[43] Z. He, J. Chen, D. Liu, H. Zhou, and Y. Kuang, "Electrodeposition of Pt-Ru nanoparticles on carbon nanotubes and their electrocatalytic properties for methanol electrooxidation," Diamond and Related Materials, vol. 13, no. 10, pp. 1764-1770, 2004.

[44] I. González-González, D. A. Tryk, and C. R. Cabrera, "Polycrystalline boron-doped diamond films as supports for methanol oxidation electrocatalysts," Diamond and Related Materials, vol. 15, no. 2-3, pp. 275-278, 2006.

[45] X. Lu, J. Hu, J. S. Foord, and Q. Wang, "Electrochemical deposition of Pt-Ru on diamond electrodes for the electrooxidation of methanol," Journal of Electroanalytical Chemistry, vol. 654, no. 1-2, pp. 38-43, 2011.

[46] H. A. Gasteiger, N. Markovic, P. N. Ross, and E. J. Cairns, "Temperature-dependent methanol electro-oxidation on wellcharacterized Pt-Ru alloys," Journal of the Electrochemical Society, vol. 141, no. 7, pp. 1795-1803, 1994.

[47] J. Zhu, F. Cheng, Z. Tao, and J. Chen, "Electrocatalytic methanol oxidation of $\mathrm{Pt}_{0.5} \mathrm{Ru}_{0.5-\mathrm{x}} \mathrm{Sn}_{\mathrm{x}} / \mathrm{C}(\mathrm{x}=0-0.5)$," Journal of Physical Chemistry C, vol. 112, no. 16, pp. 6337-6345, 2008.

[48] N. Spǎtaru, X. Zhang, T. Spătaru, D. A. Tryk, and A. Fujishima, "Platinum electrodeposition on conductive diamond powder and its application to methanol oxidation in acidic media," Journal of the Electrochemical Society, vol. 155, no. 3, pp. B264B269, 2008.

[49] H. B. Suffredini, G. R. Salazar-Banda, S. T. Tanimoto, M. L. Calegaro, S. A. S. Machado, and L. A. Avaca, "AFM studies and electrochemical characterization of boron-doped diamond surfaces modified with metal oxides by the sol-gel method," Journal of the Brazilian Chemical Society, vol. 17, no. 2, pp. 257-264, 2006.

[50] H. B. Suffredini, V. Tricoli, N. Vatistas, and L. A. Avaca, "Electro-oxidation of methanol and ethanol using a Pt$\mathrm{RuO}_{2} / \mathrm{C}$ composite prepared by the sol-gel technique and supported on boron-doped diamond," Journal of Power Sources, vol. 158, no. 1, pp. 124-128, 2006.
[51] L. C. Klein, M. Aparicio, and F. Damay, "Sol-gel processing for battery and fuel cell applications," in Sumio Sakka Applications of Sol-Gel Technology, vol. 3, Kluwer Academic Publisher, 2004.

[52] S. Sakka, Applications of Sol-gel Technology, Kluwer Academic Publisher, 2004.

[53] C. P. Ballard and A. J. Fanelli, "Sol-gel route for materials synthesis," in Chemistry of Advanced Materials, C. N. R. Rao, Ed., Blackwell Scientific Publications, 1993.

[54] H. B. Suffredini, V. Tricoli, L. A. Avaca, and N. Vatistas, "Solgel method to prepare active $\mathrm{Pt}-\mathrm{RuO}_{2}$ coatings on carbon powder for methanol oxidation," Electrochemistry Communications, vol. 6, no. 10, pp. 1025-1028, 2004.

[55] H. B. Suffredini, G. R. Salazar-Banda, and L. A. Avaca, "Enhanced ethanol oxidation on $\mathrm{PbO}_{x}$-containing electrode materials for fuel cell applications," Journal of Power Sources, vol. 171, no. 2, pp. 355-362, 2007.

[56] H. B. Suffredini, G. R. Salazar-Banda, and L. A. Avaca, "Carbon supported electrocatalysts prepared by the sol-gel method and their utilization for the oxidation of methanol in acid media," Journal of Sol-Gel Science and Technology, vol. 49, no. 2, pp. 131-136, 2009.

[57] G. R. Salazar-Banda, H. B. Suffredini, and L. A. Avaca, "Improved stability of $\mathrm{PtO}_{x}$ sol-gel-modified diamond electrodes covered with a Nafion ${ }^{\circledR}$ film," Journal of the Brazilian Chemical Society, vol. 16, no. 5, pp. 903-906, 2005.

[58] G. R. Salazar-Banda, H. B. Suffredini, M. L. Calegaro, S. T. Tanimoto, and L. A. Avaca, "Sol-gel-modified boron-doped diamond surfaces for methanol and ethanol electro-oxidation in acid medium," Journal of Power Sources, vol. 162, no. 1, pp. 9-20, 2006.

[59] G. R. Salazar-Banda, K. I. B. Eguiluz, and L. A. Avaca, "Boron-doped diamond powder as catalyst support for fuel cell applications," Electrochemistry Communications, vol. 9, no. 1, pp. 59-64, 2007.

[60] G. R. Salazar-Banda,, H. B. Suffredini, M. L. Calegaro, S. T. Tanimoto, and L. A. Avaca, "Diamond-supported binary and ternary nano-size catalyst for advanced direct-alcohol PEM fuel cells," in Proceedings of the 57th Annual Meeting of the International Society of Electrochemistry, 2006.

[61] G. R. Salazar-Banda, H. B. Suffredini, L. A. Avaca, and S. A. S. Machado, "Methanol and ethanol electro-oxidation on Pt$\mathrm{SnO}_{2}$ and $\mathrm{Pt}-\mathrm{Ta}_{2} \mathrm{O}_{5}$ sol-gel-modified boron-doped diamond surfaces," Materials Chemistry and Physics, vol. 117, no. 2-3, pp. 434-442, 2009.

[62] V. M. Swope, I. Sasaki, T. Ay, and G. M. Swain, "Conductive diamond powder: a new catalyst support for the polymer electrolyte membrane fuel cell," Electrochemical Society Transactions, vol. 3, no. 28, pp. 27-36, 2007.

[63] L. Guo, V. M. Swope, B. Merzougui et al., "Oxidation resistance of bare and pt-coated electrically conducting diamond powder as assessed by thermogravimetric analysis," Journal of the Electrochemical Society, vol. 157, no. 1, pp. A19-A25, 2010.

[64] L. Cunci and C. R. Cabrera, "Preparation and electrochemistry of boron-doped diamond nanoparticles on glassy carbon electrodes," Electrochemical and Solid-State Letters, vol. 14, no. 3, pp. K17-K19, 2011.

[65] M. Winter and R. J. Brodd, "What are batteries, fuel cells, and supercapacitors?" Chemical Reviews, vol. 104, no. 10, pp. 4245-4270, 2004.

[66] M. S. Whittingham, "Lithium batteries and cathode materials," Chemical Reviews, vol. 104, no. 10, pp. 4271-4302, 2004.

[67] J. J. Zhang and Y. Y. Xia, "Co-Sn alloys as negative electrode materials for rechargeable lithium batteries," Journal of the 
Electrochemical Society, vol. 153, no. 8, Article ID 012608JES, pp. A1466-A1471, 2006.

[68] J. Hassoun, S. Panero, and B. Scrosati, "Electrodeposited NiSn intermetallic electrodes for advanced lithium ion batteries," Journal of Power Sources, vol. 160, no. 2, pp. 1336-1341, 2006.

[69] H. Jusef, S. Panero, P. Simon, P. L. Taberna, and B. Scrosati, "High-rate, long-life Ni-Sn nanostructured electrodes for lithium-ion batteries," Advanced Materials, vol. 19, no. 12, pp. 1632-1635, 2007.

[70] X. Wang, E. Yasukawa, and S. Kasuya, "Electrochemical properties of tetrahydropyran-based ternary electrolytes for 4 V lithium metal rechargeable batteries," Electrochimica Acta, vol. 46, no. 6, pp. 813-819, 2001.

[71] M. Ishikawa, S. I. Machino, and M. Morita, "Electrochemical control of a Li metal anode interface: improvement of Li cyclability by inorganic additives compatible with electrolytes," Journal of Electroanalytical Chemistry, vol. 473, no. 1-2, pp. 279-284, 1999.

[72] K. Kanamura, H. Takezawa, S. Shiraishi, and Z. I. Takehara, "Chemical reaction of lithium surface during immersion in LiClO4 or LiPF6/DEC electrolyte," Journal of the Electrochemical Society, vol. 144, no. 6, pp. 1900-1906, 1997.

[73] R. Mogi, M. Inaba, S. K. Jeong, Y. Iriyama, T. Abe, and Z. Ogumi, "Effects of some organic additives on lithium deposition in propylene carbonate," Journal of the Electrochemical Society, vol. 149, no. 12, pp. A1578-A1583, 2002.

[74] E. Frackowiak and F. Béguin, "Electrochemical storage of energy in carbon nanotubes and nanostructured carbons," Carbon, vol. 40, no. 10, pp. 1775-1787, 2002.

[75] I. Mukhopadhyay, S. Kawasaki, F. Okino, A. Govindaraj, C. N. R. Rao, and H. Touhara, "Electrochemical Li insertion into single-walled carbon nanotubes prepared by graphite arcdischarge method," Physica B, vol. 323, no. 1-4, pp. 130-132, 2002.

[76] L. F. Li, Y. Luo, G. G. Totir, D. A. Totir, G. S. Chottiner, and D. A. Scherson, "Underpotential deposition of lithium on aluminum in ultrahigh-vacuum environments," Journal of Physical Chemistry B, vol. 103, no. 1, pp. 164-168, 1999.

[77] N. G. Ferreira, L. L. Mendonça, V. J. T. Airoldi, and J. M. Rosolen, "Electrochemical intercalation of lithium into boron-doped CVD diamond electrodes grown on carbon fiber cloths," Diamond and Related Materials, vol. 12, no. 3-7, pp. 596-600, 2003.

[78] E. C. Almeida, V. J. Trava-Airoldi, N. G. Ferreira, and J. M. Rosolen, "Electrochemical insertion of lithium into a doped diamond film grown on carbon felt substrates," Diamond and Related Materials, vol. 14, no. 10, pp. 1673-1677, 2005.

[79] A. Y. M. T. Christy, K. S. Nahm, Y. J. Hwang et al., "Lithium insertion studies on boron-doped diamond as a possible anode material for lithium batteries," Ionics, vol. 14, no. 2, pp. 157-161, 2008.

[80] S. A. Kajihara, A. Antonelli, and J. Bernholc, "Nitrogen and potential n-type dopants in diamond," Physical Review Letters, vol. 66, no. 15, pp. 2010-2013, 1991.

[81] Z. G. Lu and C. Y. Chung, "Electrochemical characterization of diamond like carbon thin films," Diamond and Related Materials, vol. 17, no. 11, pp. 1871-1876, 2008.

[82] J. Robertson, "Diamond-like amorphous carbon," Materials Science and Engineering R, vol. 37, no. 4-6, pp. 129-281, 2002.

[83] K. Honda, M. Yoshimura, K. Kawakita et al., "Electrochemical characterization of carbon nanotube/nanohoneycomb diamond composite electrodes for a hybrid anode of Li-ion battery and super capacitor," Journal of the Electrochemical Society, vol. 151, no. 4, pp. A532-A541, 2004. 


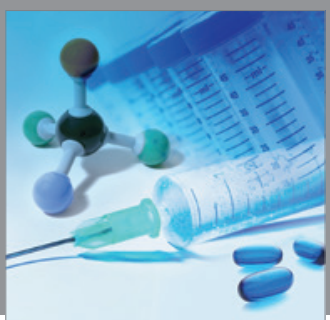

International Journal of

Medicinal Chemistry

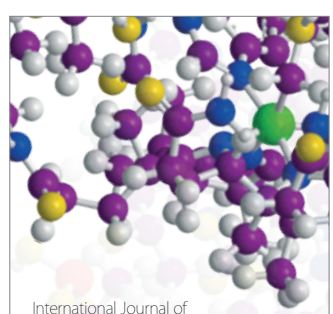

Carbohydrate Chemistry

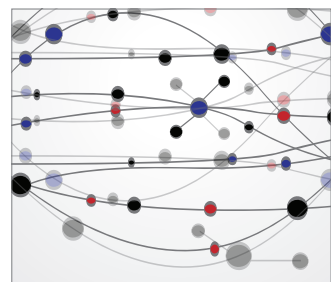

The Scientific World Journal
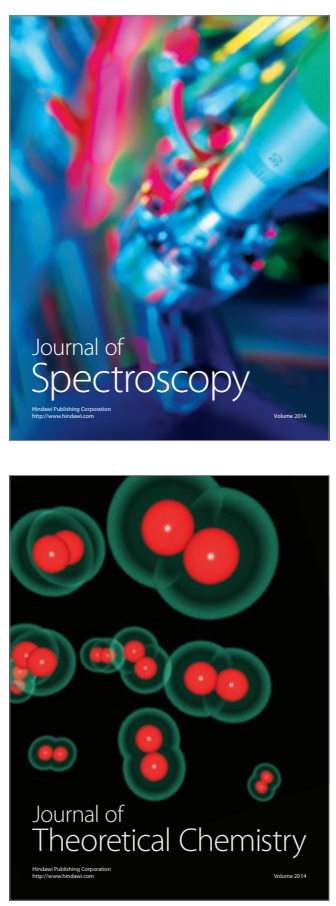
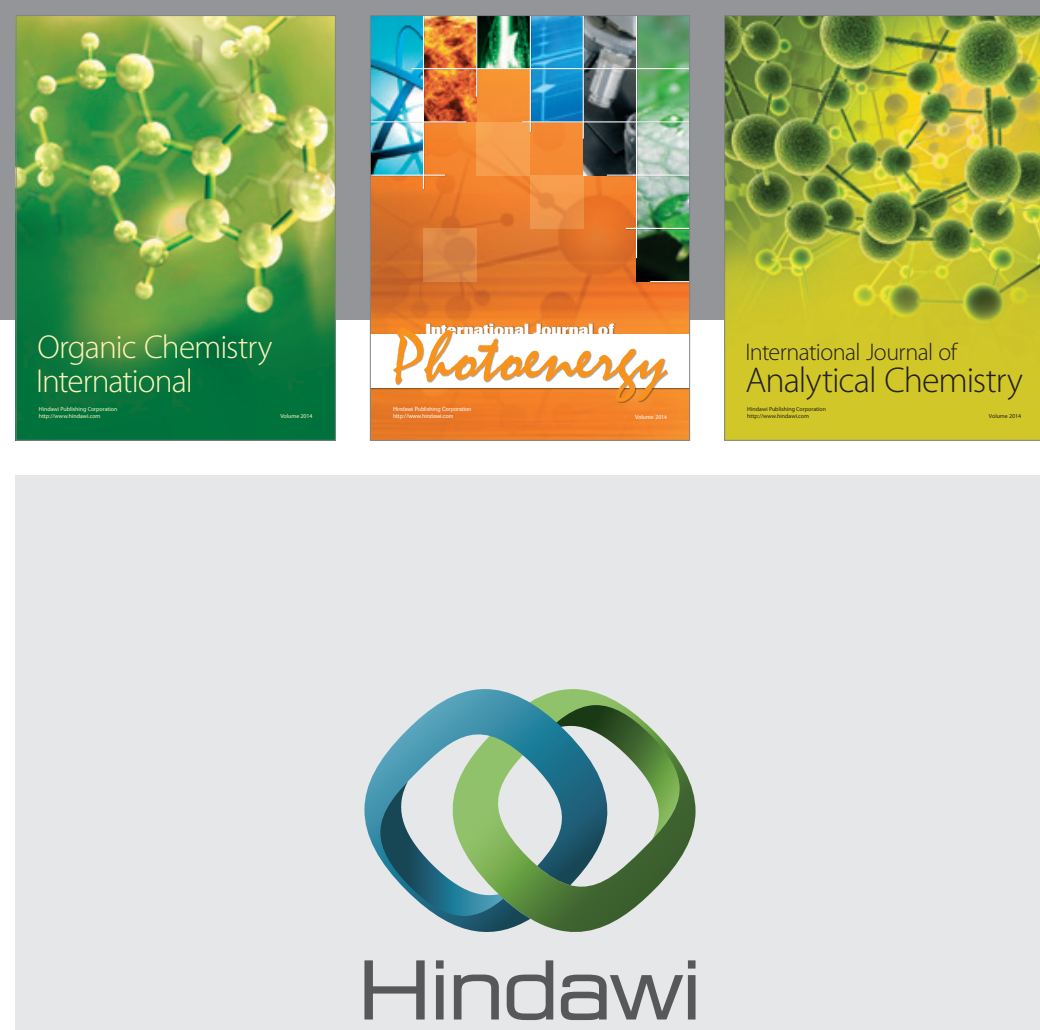

Submit your manuscripts at

http://www.hindawi.com
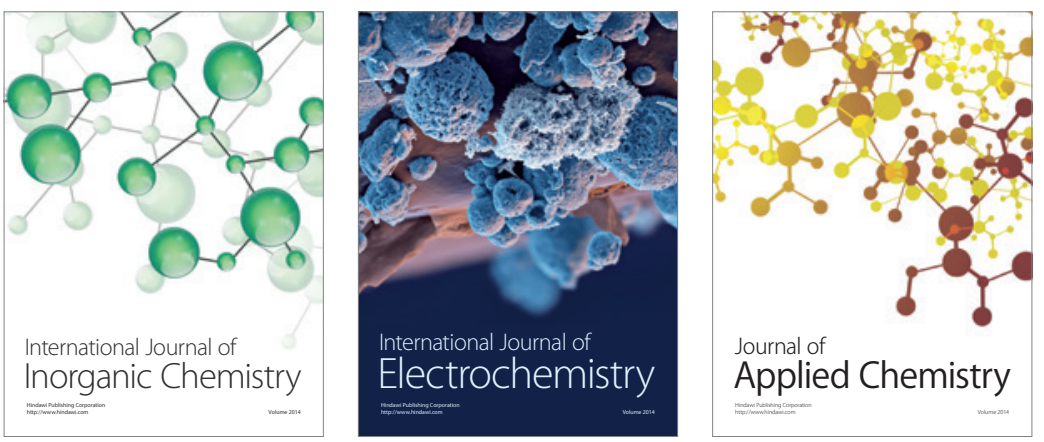

Journal of

Applied Chemistry
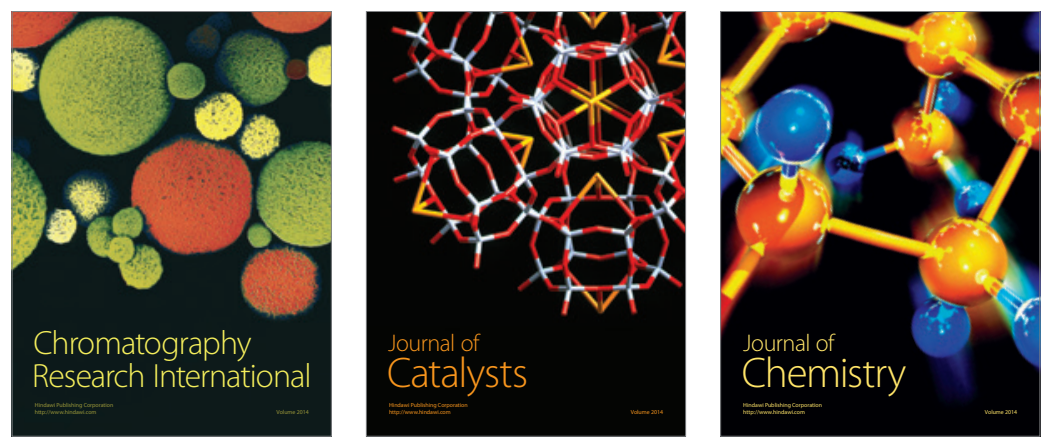
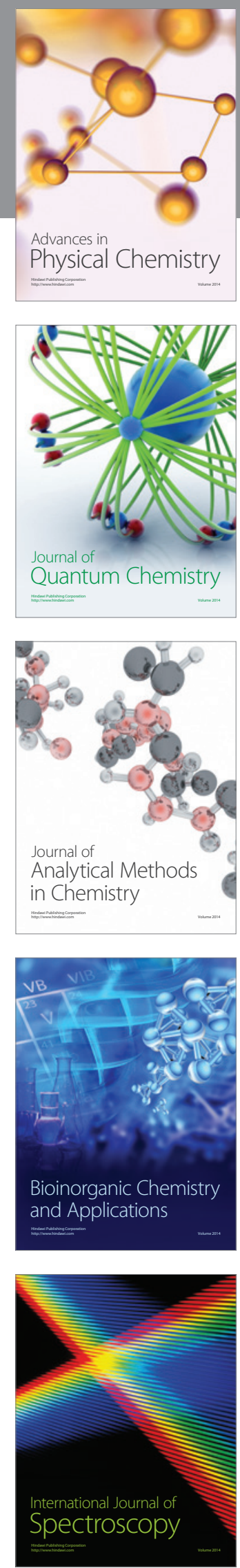